\title{
Difficulties of Computing Natural Convection Flow in an Open Cavity
}

\author{
M. Z. I. Bangalee ${ }^{1,2, *}$, Roushanara Begum ${ }^{2,3}$, M. Ferdows ${ }^{1,2}$, Md. Matiar Rahman ${ }^{4}$, Mir Shariful Islam ${ }^{2,5}$ \\ ${ }^{1}$ Department of Applied Mathematics, University of Dhaka, Bangladesh \\ ${ }^{2}$ Research Group of Fluid Flow Modeling and Simulation, Department of Applied Mathematics, University of Dhaka, Bangladesh \\ ${ }^{3}$ Department of Mathematics, American International University-Bangladesh, Bangladesh \\ ${ }^{4}$ Department of Statistics, University of Dhaka, Bangladesh \\ ${ }^{5}$ Department of Oceanography, University of Dhaka, Bangladesh
}

Copyright $\subseteq 2017$ by authors, all rights reserved. Authors agree that this article remains permanently open access under the terms of the Creative Commons Attribution License 4.0 International License

\begin{abstract}
The buoyancy driven natural convection flow in an open cavity has become an important issue to study. In this study, the difficulties of computing natural convection flow in open cavity with an extended computational domain around the cavity are reported. The $k-\varepsilon$ turbulence model is used for the computation to capture the turbulence nature of the air flow inside the cavity. ANSYS CFX software is used to solve the governing equations in this study. Effects of different aspect ratio and different temperature at the left wall and thus the temperature difference between the left and the right walls are analyzed numerically as well. Average mass flow, temperature, velocity etc. at different location in the cavity for different boundary conditions are studied and reported. A comparison between the present work and a previous work is also reported here to validate the methodology. Finally, relations among non-dimensional parameters (e.g. Ra, Re, Pr, Nu numbers) are also presented.
\end{abstract}

Keywords Computational Fluid Dynamics (CFD), Buoyancy, Mass Flow Rate, $k-\varepsilon$ Turbulence Model

\section{Introduction}

Natural convection from a cavity is one of common problems that have widespread usages in different fields. Many studies have been done to investigate heat transfer from a cavity in air standard pressure. The accuracy of simulation of buoyancy-driven natural convection in the cavity or other types of enclosure is influenced by the boundary conditions at the cavity openings in addition to other factors such as turbulence modeling.

A numerical study of three dimensional natural convection of air in a differentially heated cubical cavity with Rayleigh number $(\mathrm{Ra})$ up to $10^{10}$ is performed using the recently developed coupled discrete unified gas-kinetic scheme by Peng Wang et al. [1]. It is found that the effect on overall heat transfer decreases with increasing $\mathrm{Ra}$. An exponential scaling law between the Nusselt number and $\mathrm{Ra}$ is also found for $\mathrm{Ra}$ from $10^{3}$ to $10^{10}$.

Two-dimensional numerical analyses for a square cavity filled with air have been carried out by Markatos and Pericleous [2] over a wide range of Rayleigh numbers $10^{3} \leq$ $\mathrm{Ra} \leq 10^{8}$. The laminar flow regime was assumed up to the Rayleigh number of $10^{6}$ and for higher Rayleigh numbers, the $k-\varepsilon$ turbulence model was used. For $10^{3} \leq \mathrm{Ra} \leq 10^{6}$ and a Boussinesq fluid of Prandtl number $\operatorname{Pr}=0.71$, a set of benchmark solutions has been suggested by De Vahl Davis [3]. By resorting to systematic grid refinement practice and by concurrent use of the Richardson extrapolation to obtain grid independent data, these solutions were claimed to be within accuracy of $1 \%$.

Simulations were carried out for natural convection in a square cavity using finite volume based computational procedure with biased quadratic elements to investigate the influence of convective boundary conditions at bottom wall by Aswatha et al. [4]. It was observed from this study that the heat transfer was primarily due to conduction for Rayleigh number up to $10^{4}$. Convection dominant heat transfer was observed at higher $R a$ values. The intensity of circulation was observed to be increasing with the increase in Rayleigh number. The average heat transfer rate at the bottom wall was found to be invariant for all values of heat transfer coefficient for $R a$ up to $10^{4}$. The power law correlations between average Nusselt number and Rayleigh numbers were presented for convection dominated regimes.

The steady state investigation of the natural convection heat transfer inside the cavity under uniform heat fluxes, different opening ratios, tilt angles and cavity aspect ratios for top and center opening positions were investigated by Ayla Dogan et al. [5]. Temperature and velocity fields driven by buoyancy forces in a cubic enclosure heated from a vertical side-wall were investigated numerically and experimentally at $R a=1.3 \times 10^{7}$ by N. Alpay Kurekci and Oktay Ozkan [6]. Numerical and experimental results for the mid-plane of the enclosure were compared and found to be in general agreement with each other. Some discrepancies have been observed between the numerical and experimental results. These discrepancies may be attributed to the differences in boundary conditions. It was suggested that the 
velocity field near the heated and cooled vertical walls is not overly sensitive to the boundary conditions on the remaining four walls.

Among the different CFD methods, Jiang et al. [7] and Wei Zhang et al [8] studied the Large Eddy Simulation methods for buoyancy driven flow. A high-resolution, finite difference numerical study was reported by H.S. Lee and H.S. Yoon [9] on three-dimensional steady-state natural convection of air, for two Rayleigh numbers, in a cubical enclosure, which is heated differentially at one side walls. The Rayleigh number ranges from $10^{3}$ to $10^{6}$. The Prandtl number of the fluid is held fixed at 0.71. Comprehensive details of the flow and temperature fields were presented by displaying elaborate three-dimensional color graphics and illustrative field quantities.

St. Venant's principle, often invoked in solid mechanics, may also be used in fluid mechanics: if the artificial boundaries are placed sufficiently far away from the channel apertures, the velocity and temperature distributions at the entrance/exit of the channel are no longer affected by the applied boundary conditions [10]. The issue now raised is how far the artificial open extensions must be placed in order that the physical quantities in the inlet/outlet sections become insensitive to the conditions set at boundaries. Although this approach seems attractive, the increase in size of the computational domain proves to be expensive, both in memory and in computational time. For these reasons, the domain extensions are often either relatively reduced or large but coarsely discretized. The shapes of the walls at the entrance region, with sharp angles or smooth rounded surfaces, affect also significantly the fluid flows and heat transfer. Using entrance walls with right angles, Naylor et al. [11] predicted a fluid separation at the channel inlet which is approximately correlated with the dimensional flow rate. Their inlet boundary conditions were based on JeffreyHamel flow which consists in a similarity solution of isothermal flow caused by the presence of a source or sink at the point of intersection of two walls.

Natural convection and entropy generation due to the heat transfer and fluid friction irreversibility's in a three-dimensional cubical cavity with partially heated and cooled vertical walls has been investigated numerically using the finite volume method by Abdullah A. A. A. Al-Rashed et al. [12]. The results explain that the total entropy generation rate increases when the Rayleigh number increases. While, the Bejan number decreases as the Rayleigh number increases. It is also found that the arrangements of heating and cooling regions have a significant effect on the fluid flow and heat transfer characteristics of natural convection and entropy generation in a cubical cavity.

A finite volume based computational procedure was used to investigate natural convection in cavities at different aspect ratios $(\mathrm{H} / \mathrm{L})$ varying from 0.5 to 2 by Aswatha et al. [13]. It was observed that, the sinusoidal temperature produced greater heat transfer rate at the center of the bottom wall. Uniform temperature at the bottom wall gave higher Nusselt number compared to the sinusoidal and linearly varying temperature. The average Nusselt number for bottom wall was increasing with the increase of aspect ratio, where as it was decreasing for side walls.

As a mechanism of heat transfer, natural convection has a lot of benefits. In many parts, convective heat transfer plays an important role in heat transferring. In some cases rate of heat transfer is important and it's vital to predict it. Various parameters effects on the rate of heat transfer. It is obvious that convection is caused by density variation of fluid.

A three dimensional cavity enclosed with another cavity equally distanced from all the corresponding parallel sides of the inner cavity is considered here to study. Difficulties of computing natural convection flow in this cavity are studied here numerically. The flow is considered to be steady, incompressible, viscous and turbulent. The $k-\varepsilon$ turbulence model with ANSYS CFX [14] software is used for simulation to capture the turbulent nature of the flow. Non-uniform structured mesh is generated in the cavity. Effects of different boundary conditions such as, aspect ratio, different temperature difference between the hot and cold walls, heat flux etc. are studied and reported. Effects of these conditions are observed on mass flow and temperature at different height of the cavity and streamlines, velocity vectors etc. on a vertical plane inside the cavity. To validate the method, a comparison of the present results with a previous work is also presented here. Two relations among non-dimensional parameters such as Nusselt number, Reynolds number, Rayleigh number, Prandlt number are also reported in this study.

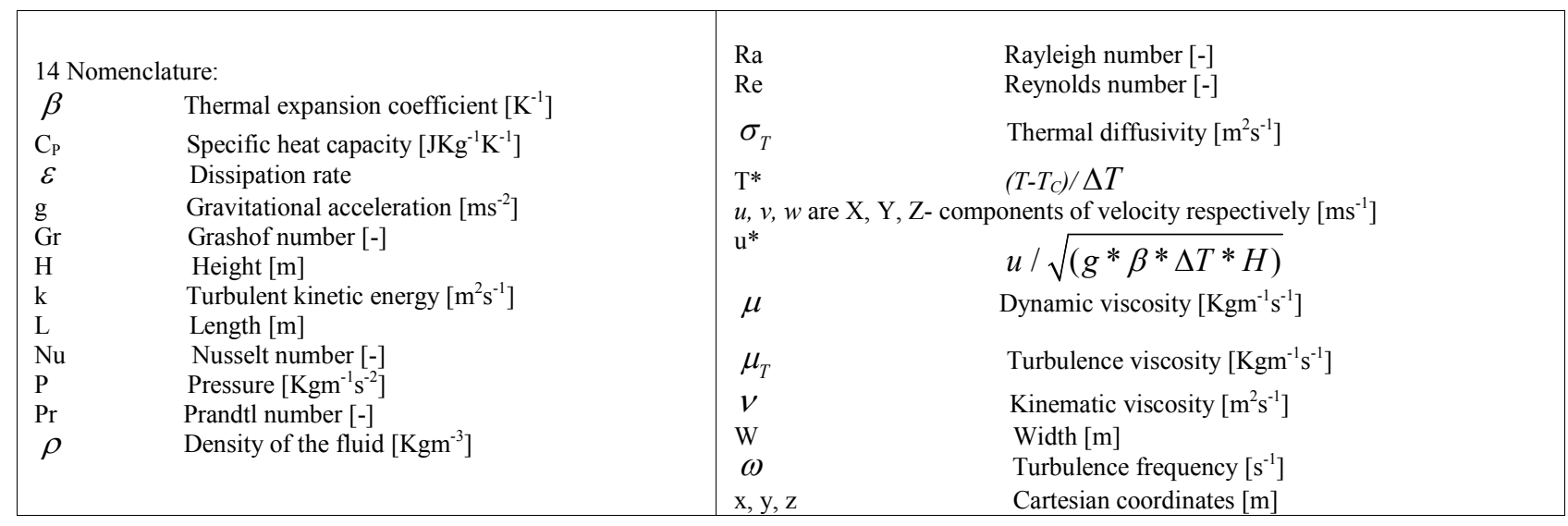




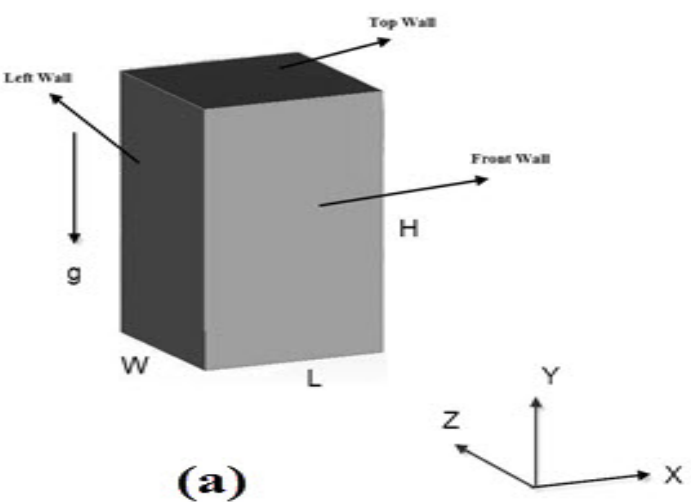

(a)

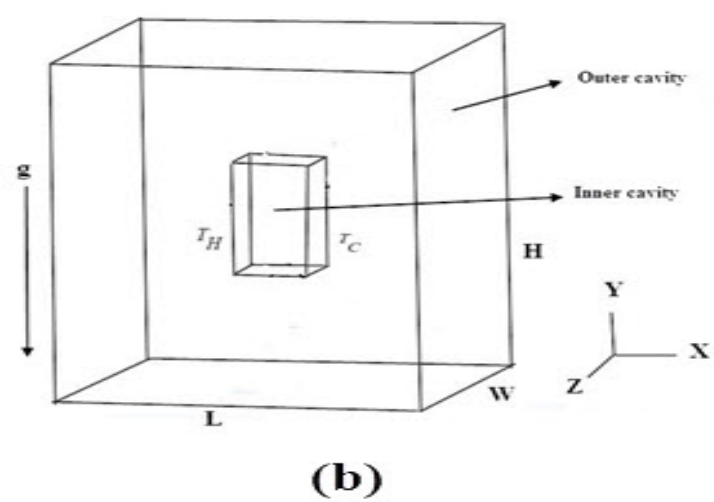

Figure 1. (a) Studied cavity and (b) Studied cavity with equally distant outer cavity

\section{Description of the Model}

Buoyancy-driven natural convection flow in a three dimensional open cavity is studied here numerically. Heat is imposed at the left wall of the cavity and the right wall is kept at a constant temperature $\left(\mathrm{T}_{\mathrm{c}}\right)$. Heat flux is used at all other walls of the cavity. Another cavity is considered outside this cavity with all the sides at equal distance from the corresponding parallel sides of the inner cavity. It is considered to observe the effects of natural convection heat transfer in air flow. In particular, the dimension of the inner cavity is assumed to be $0.5 \mathrm{~m}$ (length) $\times 0.5 \mathrm{~m}$ (width) $\times$ $1.0 \mathrm{~m}$ (height) and the outer cavity is assumed to be $1 \mathrm{~m}$ distant from all the corresponding parallel sides of the inner cavity. A figure of this geometry is presented in Figure 1.

\section{Numerical Method}

The following steps are discussed to simulate the problem of the system numerically:

\subsection{Computational Fluid Dynamics}

The application of computational fluid dynamics (CFD) methodologies has become very popular due to the upgrade of computational resources and the improvement of turbulence models, both allowing for a more detailed description of the induced flow field.

Bejan and Kimura [15] conducted both theoretical and experimental studies to investigate the penetration of natural convection into a horizontal cavity. It was shown that the flow consists of a horizontal counter flow that penetrates the cavity over a distinct length, which is proportional to the cavity height and the square root of the Raleigh number. Two dimensional open-ended structures were studied by $\mathrm{K}$. Khanafer and K. Vafai [16] to obtain an accurate set of effective boundary conditions for flow and temperature fields at the aperture plane for a wide range of pertinent parameters such as Rayleigh number, Prandtl number, and aspect ratio.

Comprehensive comparisons for the streamlines and the isotherms within the enclosure were presented for various controlling parameters between the two-dimensional closed ended model and the fully extended domain utilizing the far field boundary conditions.

A three dimensional cavity with an extended computational domain is assumed here to capture the flow phenomena inside and outside the cavity with proper boundary conditions.

\subsection{Governing Equations and Boundary Conditions}

CFD is based on the resolution of the governing equations which describe the flow field in the computational domain, namely the continuity equation for mass transfer, the Navier-Stokes equation for momentum transfer and the thermal energy equation for heat transfer. These equations for this problem can be written as follows:

Continuity equation:

$$
\frac{\partial}{\partial x_{j}}\left(u_{j}\right)=0 ; j=1,2,3 ;
$$

Momentum equation:

$$
\begin{aligned}
& \rho u_{j} \frac{\partial}{\partial x_{j}}\left(u_{i}\right)=-\frac{\partial p}{\partial x_{i}}+\frac{\partial}{\partial x_{j}}\left[\left(\mu+\mu_{T}\right) \frac{\partial u_{i}}{\partial x_{j}}\right]+ \\
& \rho_{r e f} g_{i} \beta\left(T-T_{r e f}\right) ; i=1,2,3 ; j=1,2,3 ;
\end{aligned}
$$

Energy equation:

$$
u_{j} \frac{\partial}{\partial x_{j}}(T)=\frac{\partial}{\partial x_{j}}\left[\left(\frac{v}{\operatorname{Pr}}+\frac{v_{T}}{\sigma_{T}}\right) \frac{\partial T}{\partial x_{j}}\right] ; j=1,2,3 ;
$$

According to the $k-\varepsilon$ model, $\mu_{T}$ can be expressed as follows:

$$
\mu_{T}=C_{\mu} \rho \frac{k^{2}}{\varepsilon}
$$

$k$ and $\varepsilon$ can be obtained from the following equations:

$$
\begin{gathered}
\frac{\partial}{\partial x_{j}}\left(\rho u_{j} k\right)=\frac{\partial}{\partial x_{j}}\left[\left(\mu+\frac{\mu_{T}}{\sigma_{k}}\right) \frac{\partial k}{\partial x_{j}}\right]+P_{k}-\rho \varepsilon ; \\
j=1,2,3 ;
\end{gathered}
$$




$$
\begin{gathered}
\frac{\partial}{\partial x_{j}}\left(\rho u_{j} \varepsilon\right)=\frac{\partial}{\partial x_{j}}\left[\left(\mu+\frac{\mu_{T}}{\sigma_{\varepsilon}}\right) \frac{\partial \varepsilon}{\partial x}\right]+C_{1} \frac{\varepsilon}{k} P_{k}-C_{2} \rho \frac{\varepsilon^{2}}{k} \\
j=1,2,3
\end{gathered}
$$

Here $\mathrm{P}^{k}$ is the production rate of turbulent kinetic energy which depends on the turbulent viscosity and velocity distribution. The values of all the empirical constants used in previous equations are presented in Table 1.

Table 1. Empirical constants used in $k-\varepsilon$ model

\begin{tabular}{|c|c|}
\hline $\mathrm{C}^{\mu}$ & 0.09 \\
\hline $\mathrm{C}_{1}$ & 1.44 \\
\hline $\mathrm{C}_{2}$ & 1.92 \\
\hline$\sigma_{k}$ & 1.0 \\
\hline$\sigma_{\varepsilon}$ & 1.3 \\
\hline
\end{tabular}

\subsubsection{Boundary Conditions}

An extended computational domain around the physical domain of the cavity where every surface of the extended domain is $1 \mathrm{~m}$ far from the nearest parallel surface of the physical domain is chosen as the reference case. Other boundary conditions are:

Inner cavity:

(i) Left wall temperature: $45^{\circ} \mathrm{C}$,

(ii) Right wall temperature: $25^{\circ} \mathrm{C}$,

(iii) All other walls: Zero heat flux.

Outer Cavity:

(i) Top and Bottom wall: Open at $25^{\circ} \mathrm{C}$ surrounding temperature,

(ii) All the walls: adiabatic.

\subsubsection{Turbulence Model}

The natural convection flow behaves as laminar flow for Rayleigh number up to $10^{6}$ [2]. For higher Rayleigh number the flow is considered to be turbulent.

G. Evola et al. [17] studied wind driven natural ventilation in a cubic building. The two equation $k-\varepsilon$ model and the Renormalization Group (RNG) theory were used to capture the flow phenomena. A computational fluid dynamics (CFD) method was developed by M.Z.I. Bangalee et al. [18] to solve the buoyancy-driven flow accurately when imposing the boundary conditions at the openings of the original model is avoided. A $k-\omega$ based shear stress transport (SST) turbulence model was chosen to simulate the problem. Allocca et al. [19] also studied the buoyancy driven flow by using $k-\varepsilon$ turbulence model.

In this study the Rayleigh number is assumed to be greater than $10^{8}$. That is, the air flow assumed here is turbulent. The $k-\varepsilon$ turbulence model is used in this study instead of RNG $k-\varepsilon$ and $k-\omega$, to get faster (with less iteration) converged result than other models.

\subsection{Numerical Solution}

ANSYS CFX solver manager 12.0 [14] has been used in this study to solve the set of equations provided by $k-\varepsilon$ turbulence model introduced in the previous section. ANSYS CFX is CFD software, which is based on the finite volume method and used to get the solution at each node of the computational domain. The convergent and grid independent solution is obtained with residual target $10^{-4}$. The convergence history of the flow components and the turbulence quantities are delineated in Figure 2.

\subsection{Grid Distribution}

It is obvious that structured mesh may predict the flow properties more accurately than unstructured mesh does. However, a numerical simulation using structured mesh consumes more CPU time than that of unstructured mesh. Since the simulation of natural convection is very sensitive, it is desired to simulate the case using structured mesh. To discretize the computational domain ICEM CFD [14] software is used. Non-uniform structured mesh with finest possible grid containing about 0.5 million hexahedral elements is generated in inner cavity. A minimum spacing $1 \mathrm{~mm}$, stretching factor of 1.2 and 26 grids in the radial direction up to a certain distance are generated. 45 uniform grids are used along the length (X-direction) and width (Z-direction) of the cavity. 70 uniform grids are used along the height (Y-direction) of the cavity (Figure 3 ).

In the outer cavity, non-uniform structured mesh is used and comparatively denser grids are generated adjacent to all walls of the inner cavity. It is used to capture the flow characteristics just outside the inner cavity. In total, about 0.46 million hexahedral elements are used with a minimum spacing $1 \mathrm{~mm}$ and a stretching factor 2 in all axial direction. The grid distribution in both of this cavity is shown in Figure 3 . The average grid quality is found $0.85-0.95$ in all cases.

\section{Validation of Methodology}

A finite volume based computational procedure is used in this study, to investigate the natural convection flow in $3 \mathrm{D}$ open cavity. The flow here is assumed to be turbulent. To observe the flow characteristics inside the cavity, $k-\varepsilon$ turbulence model is used. 


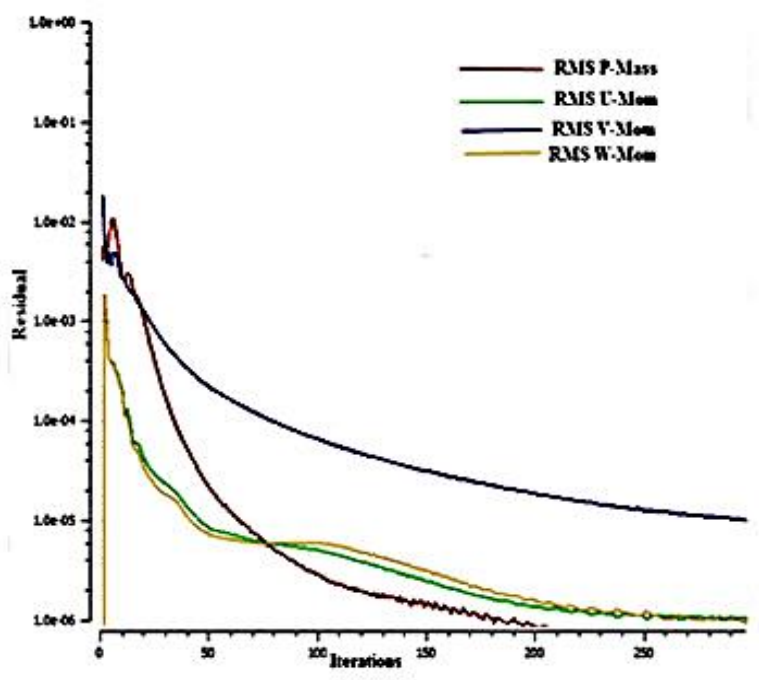

(a)

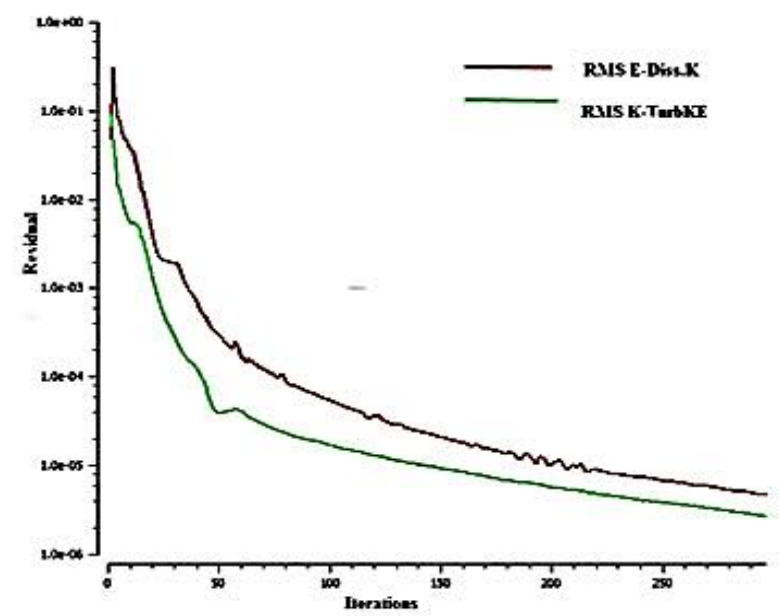

(b)

Figure 2. (a) Convergence history of P-Mass and U, V, W Momentum and (b) Convergence history of RMS E-Diss.K and K-TurbK.

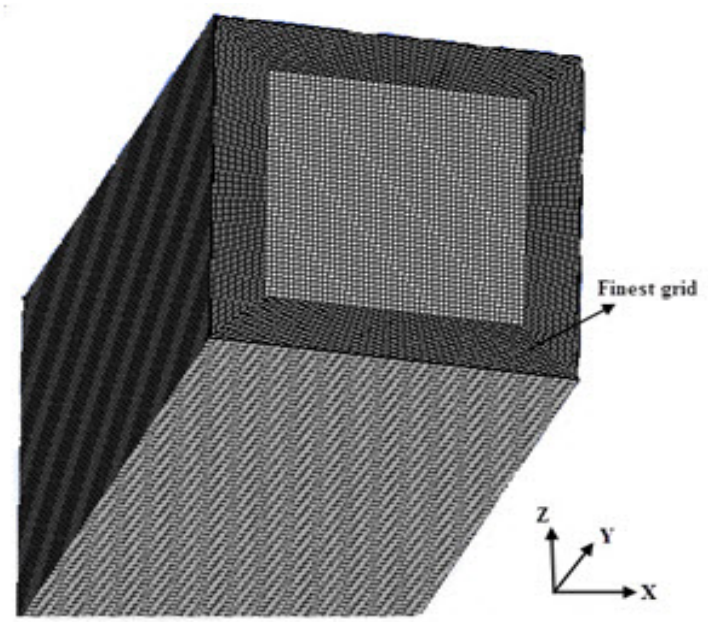

(a)

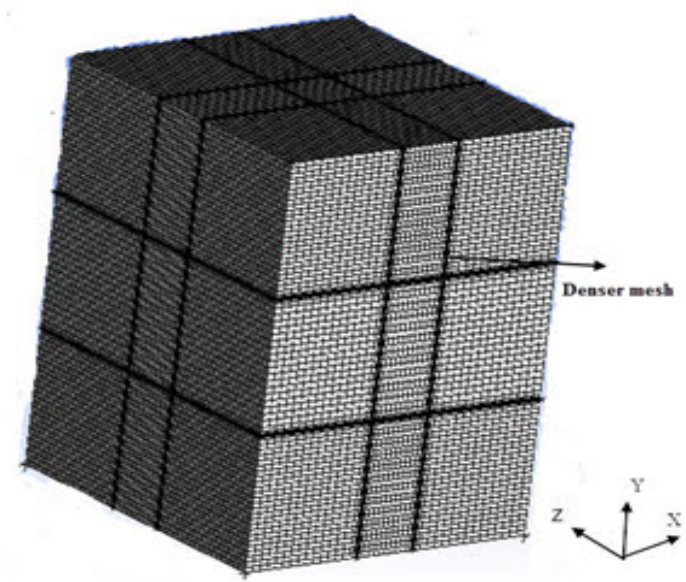

(b)

Figure 3. (a) Grid distribution on studied cavity and (b) Grid distribution on equally distant outer cavity

Turbulent natural convection flow in a cubic cavity is analyzed both numerically and experimentally by V. M. Maytorena et al. [20]. Numerical simulations have been carried out for natural convection flow in a square cavity by G. Barakos et al. [20]. The control volume method is used for a series of Rayleigh numbers reaching values up to $10^{10}$, to solve the conservation equations for both the laminar and turbulent flows. The $k-\varepsilon$ turbulence model has also been used for turbulence modeling with and without logarithmic wall functions.

In this section, a comparative discussion with Maytorena's [20] and Barakos's work [21] is presented.

\subsection{Comparison of the Work Reported by V. M. Maytorena et al. [20]}

The study of turbulent natural convection on a cubic cavity with dimension $1 \mathrm{~m} \times 1 \mathrm{~m} \times 1 \mathrm{~m}$ is performed here and the result is compared with the numerical and experimental results reported by V. M. Maytorena et al. [20] for Raleigh number $1.66 \times 10^{11}$. In this study, the thickness of each wall is considered to be $150 \mathrm{~mm}$. The height of the cavity from the ground is considered as $300 \mathrm{~mm}$. An extended computational domain around this cavity is also assumed here having each sides at $2 \mathrm{H} \mathrm{m}$ far from all the parallel sides of the cavity, where $\mathrm{H}=1 \mathrm{~m}$ is assumed as the reference length. Figure 4 shows the schematic view of this cavity.

At the left wall of the cavity a constant heat flux of 55 $\mathrm{W} / \mathrm{m}^{2}$ is used. Right wall is assumed to be open at $300 \mathrm{~K}$ temperature. All other walls of this cavity are assumed to be adiabatic. Left, right and top wall of the extended computational domain are assumed to be open at $300 \mathrm{~K}$ temperature. Figure 5 shows comparison of the temperature profile at different height of the cavity. Temperature is observed to be about $2 \mathrm{~K}$ less than the experimental and numerical study. This discrepancy may be occurred because of the temperature setup. The room temperature in the Maytorena's study was not precisely mentioned. If the temperature were set to $302 \mathrm{~K}$, more accurate result would have found here. 


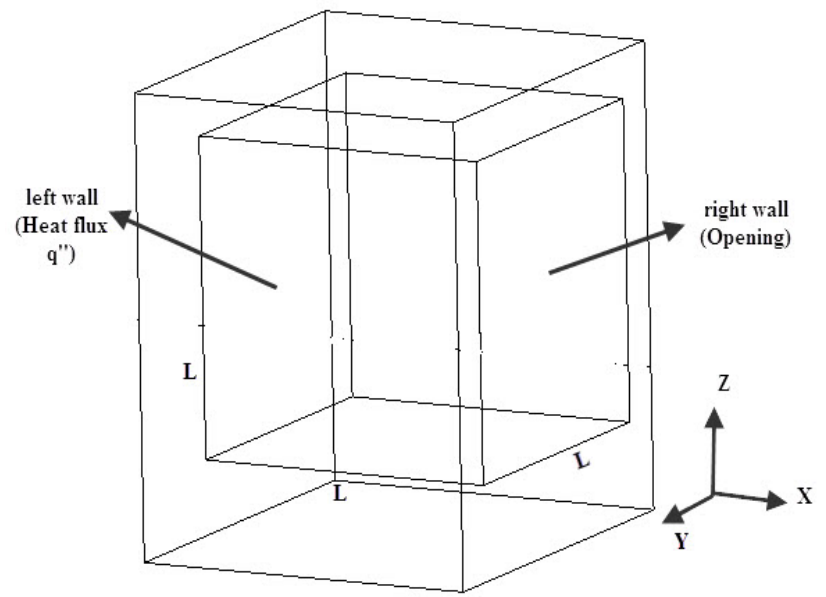

Figure 4. Schematic view of the Model
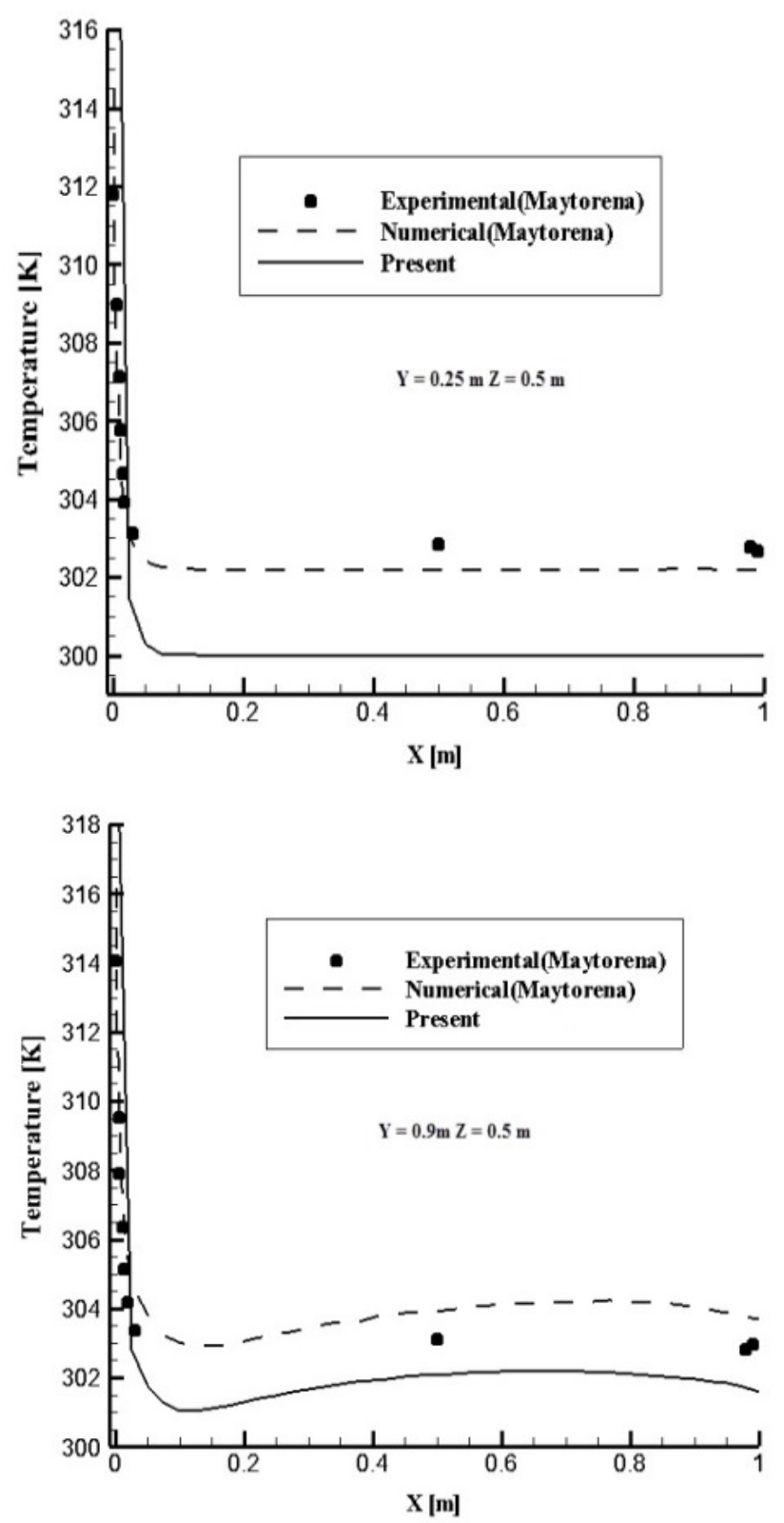

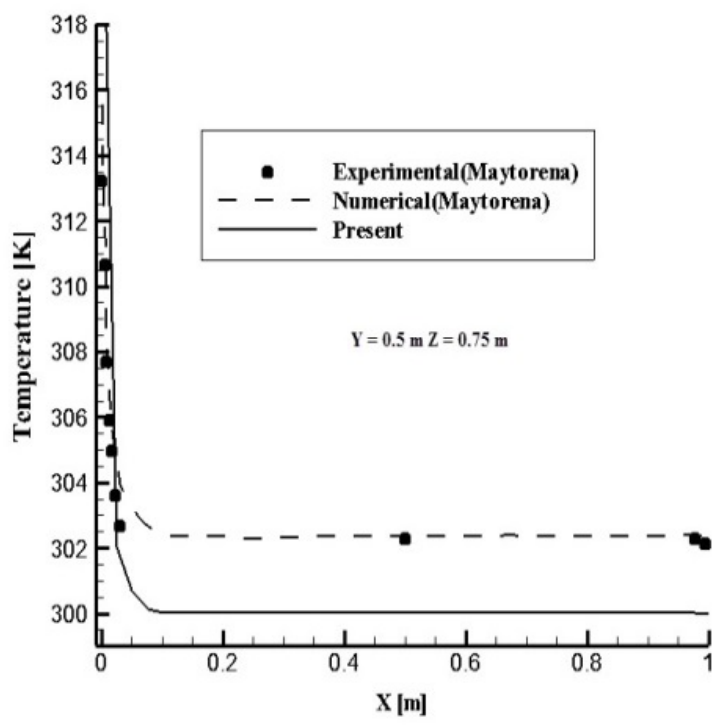

Figure 5. Comparison of temperature profile for $\mathrm{Ra}=1.66 \times 10^{11}$ at different position of the cavity.

\subsection{Comparison with the Result Reported by Barakos et al. [21]}

Barakos et al. [21] studied the buoyancy driven laminar and turbulent air flow in a two dimensional closed square cavity. Boundary conditions were taken as shown in Figure 6. $293 \mathrm{~K}$ was taken as reference temperature, between the hot and cold wall temperature difference was kept $20 \mathrm{~K}$ and $\mathrm{Ra}$ number was varied from $10^{3}$ to $10^{10}$.

Figure 7 shows the comparison between u-velocity component and temperature distribution for $k-\varepsilon$ solution. Discrepancy is found in both the cases. It is because, in a two dimensional cavity the effect of flow along $\mathrm{Z}$-axis is not considered. So the discrepancy with present study is occurred due to $3 \mathrm{D}$ effect, discretization error, lack of sufficient convergence.

In fact, in a two dimensional cavity the fluid no longer remains turbulent and it behaves like laminar flow. That's why the similarity with the results is found with laminar solution and is shown in Figure 8. So it can be concluded that this numerical method may be able to solve the buoyancy driven open cavity flow problem accurately.

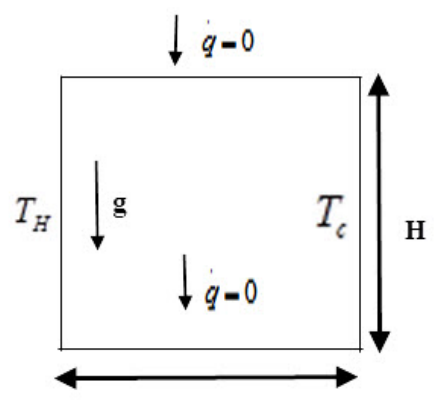

W

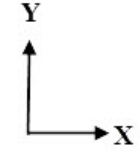

Figure 6. Two dimensional square cavity with relevant notation and boundary conditions [20]. 


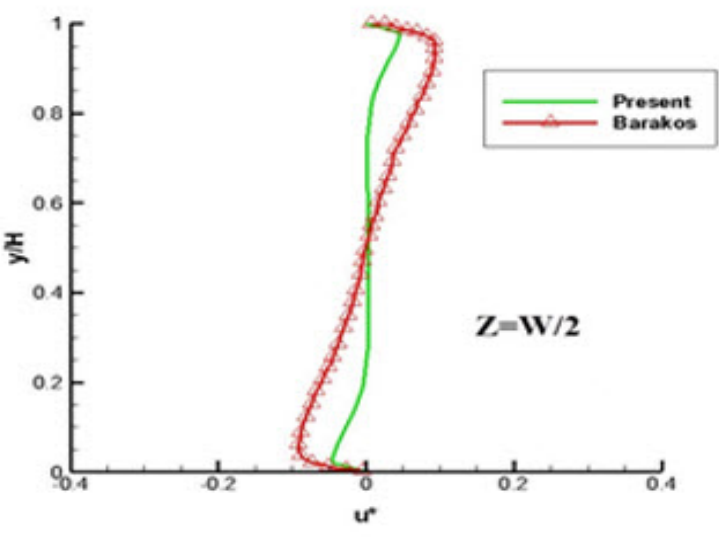

(a)

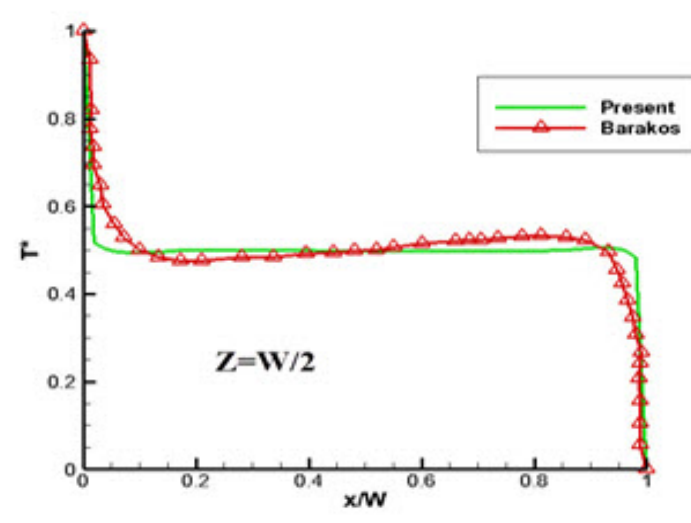

(b)

Figure 7. (a) Comparison of u-velocity component and (b) temperature distribution at mid length of the cavity $(k-\varepsilon)$ solution

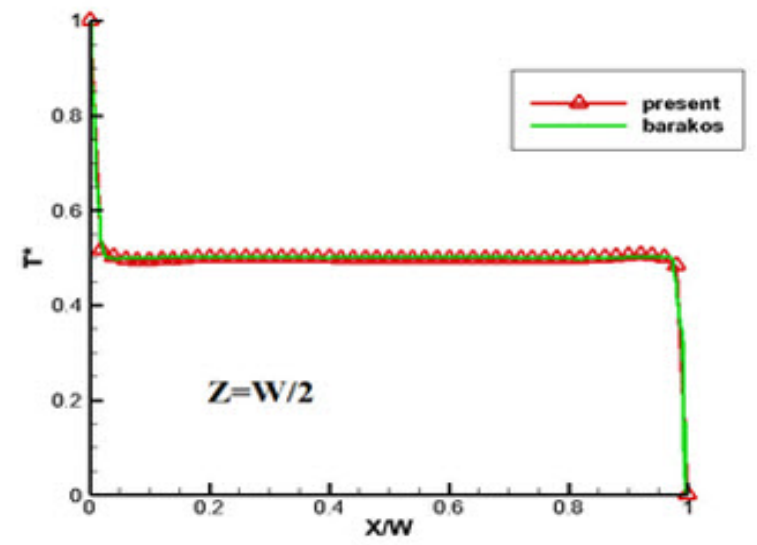

(a)

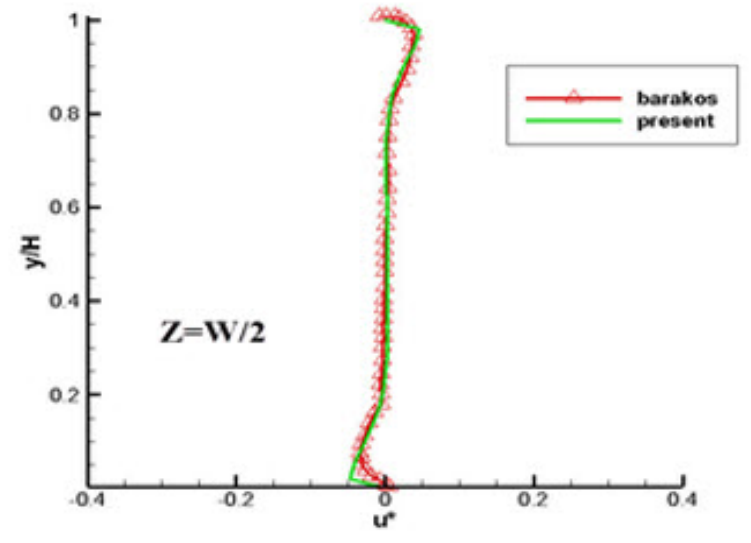

(b)

Figure 8. (a) Comparison of temperature distribution and (b) u-velocity component at mid height of the cavity (laminar solution)

\section{Results and Discussion}

Buoyancy driven natural convection flow in a three dimensional open cavity is studied here numerically. The effects of different boundary conditions on this flow are discussed here as follows:

\subsection{The Flow and Heat Transfer Characteristics}

An extended computational domain around the physical domain of the cavity where every surface of the extended domain is $1 \mathrm{~m}$ far from the nearest parallel surface of the physical domain is chosen as the reference case. The left wall and right wall temperature of the inner cavity are kept at $45^{\circ} \mathrm{C}$ and $25^{\circ} \mathrm{C}$, respectively. Zero heat flux is used at all other walls. All the walls of the outer cavity are assumed to be adiabatic except the top and bottom walls. The top and bottom walls are kept open at surrounding temperature $25^{\circ} \mathrm{C}$. Figure 9a shows the temperature and velocity profile at different height of the inner cavity. The temperature profile becomes uniform at a distance of $0.2375 \mathrm{~m}$ from the hot wall to cold wall (Figure 9a). The velocity profile from bottom to top wall inside the cavity gradually increases adjacent to the hot wall and decreases adjacent to the cold wall (Figure 9a).
The opening positions are located at bottom and top of the cavity. All other sides are closed. So the flow is entering through the bottom and passing through the top. Figure $9 \mathrm{~b}$ shows the temperature and velocity contour, streamlines and velocity vector on a vertical plane located at middle width of the inner cavity. From the figure of temperature and velocity contour, it is observed that the temperature and velocity are higher at adjacent to the hot wall of the cavity. That means, the temperature and velocity adjacent to the heated wall are developing. The temperature contour at mid width on a vertical plane also shows that, adjacent to the hot wall the temperature is higher and it is observed up to a very short length along $\mathrm{X}$-axis where heat is imposed and its adjacent area.

The streamlines show that the flow pattern on the plane passing through the top adjacent to the cold wall is observed to be turbulent. It also indicates that the flow is not fully developed. The velocity induced by natural convection is generally large in magnitude. Larger velocity is observed at top and adjacent to the hot wall. The velocity vector shows the direction of the flow from the bottom opening to top opening position and it becomes chaotic inside the cavity with the increase of distance from the hot wall. 

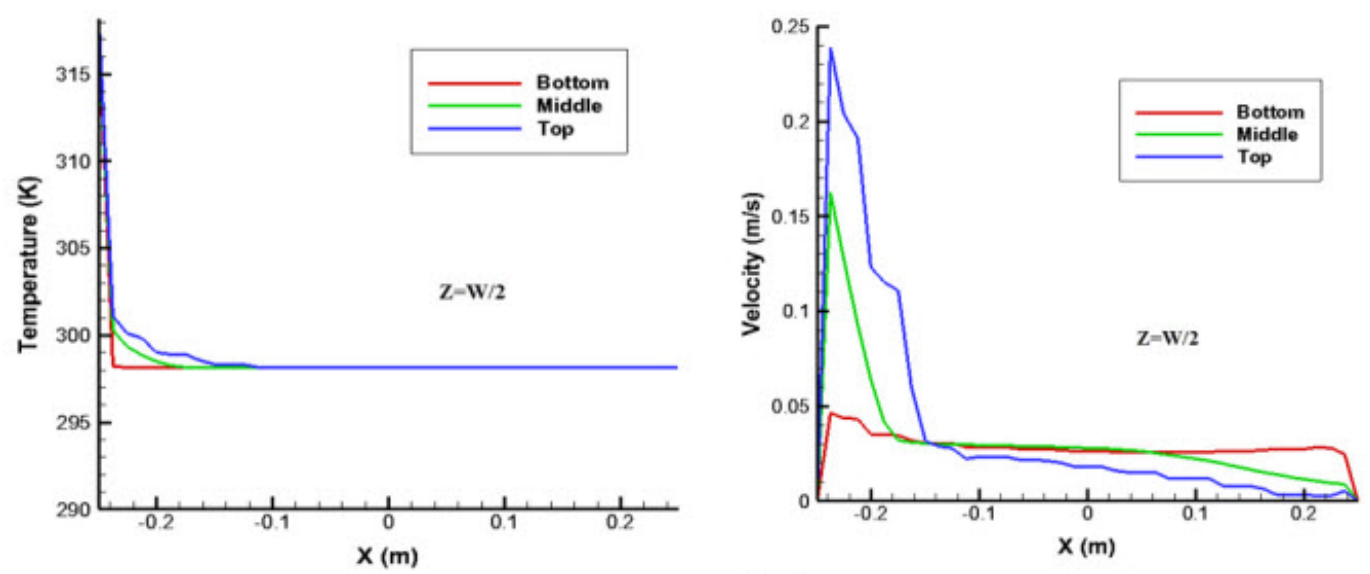

(a)
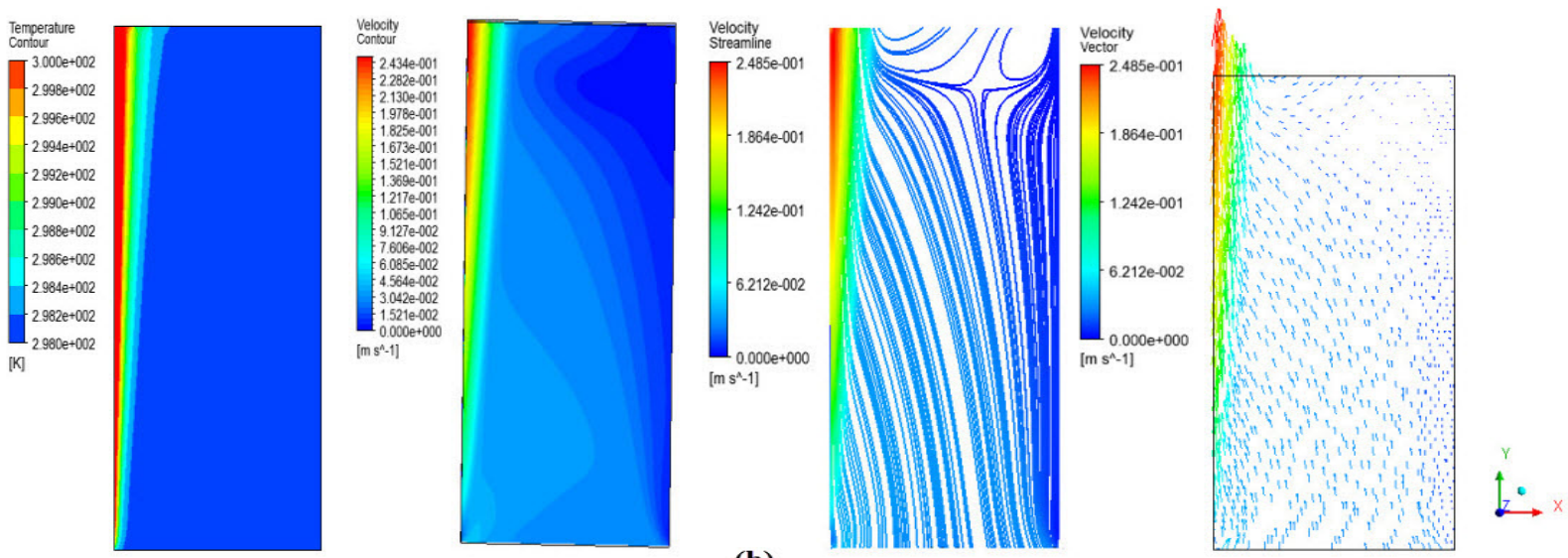

Figure 9. (a) Temperature and velocity profile and (b) temperature contour, velocity contour, streamline, velocity vectors respectively on a vertical plane inside the cavity

\subsection{Effects of Aspect Ratio}

Aspect Ratio (AR) is defined as the ration of height and length of the cavity $(\mathrm{H} / \mathrm{L})$. It has significant effects on heat transfer characteristics. Aswatha et al. [21] studied the effects of aspect ratio and thermal boundary conditions on natural convection in two dimensional cavities. The flow and heat transfer characteristics in cavities for uniform, sinusoidal and linearly varying temperature at the bottom wall, symmetrically cooled side walls with uniform temperature and insulated top wall for the range of Ra from $10^{3}$ to $10^{7}$ for aspect ratios ranging from 0.5 to 2 were reported in this study.

In the present study, different aspect ratio ranging from 0.5 to 5 is obtained by changing only the height of the cavity from $0.25 \mathrm{~m}$ to $2.5 \mathrm{~m}$ keeping the length $(0.5 \mathrm{~m})$ and width $(0.5 \mathrm{~m})$ of the cavity unchanged. It is found that mass flow, temperature, heat flux, etc. have different effects at different aspect ratio. Local Nusselt numbers:

$$
\left(N u=\frac{h D}{k} ; h=\frac{q}{\Delta T}\right)
$$

at mid height of the hot wall (left wall) of the inner cavity are computed to observe the heat transfer characteristic with the changing of aspect ratio (Figure 10a). It is found that the local Nusselt number increases with the increase of aspect ratio. Minimum local Nusselt number is computed at the center of the hot wall. Decreasing and increasing trends are observed for local Nusselt number along the hot wall of the cavity at mid height of the hot wall. That is, the local $\mathrm{Nu}$ number is increasing towards the front and rear wall.

Average heat flux at hot wall of the cavity increases with the increase of aspect ratio (Figure 10b). Average heat flux at aspect ratio 0.5 is found to be $19.8393 \mathrm{Wm}^{-2}$ and for aspect ratio 5 it becomes $41.826 \mathrm{Wm}^{-2}$ which is about 2 times of the heat flux for the aspect ratio 0.5.

Average mass flow and temperature with different aspect ratio are reported in Table 2. It is observed that mass flow gradually increases and temperature gradually decreases at the bottom wall with the increase of aspect ratio until the AR 4. With more increase in AR, mass flow and temperature again decreases may be because of taller cavity and more air inside the cavity.

To capture the nature of the flow for the changing of aspect ratio, the velocity vectors and the streamlines are observed in this section (Figure 12). From these velocity vectors, it is seen that the velocity of the fluid adjacent to the left wall is increasing with the increase of aspect ratio as the mass flow from bottom to top wall is increasing. It can be concluded from the streamlines that, with the increasing of aspect ratio transition from laminar to turbulent of the fluid occurs.

The temperature and the velocity profile at different height of the cavity are shown in Figure 11. The temperature distribution at the mid width of the bottom wall for all aspect 
ratio remains identical. But some discrepancies are observed at the mid height and top wall of the cavity. The temperature adjacent to the hot wall gradually increases with the increase of aspect ratio (Figure 11a). The velocity at bottom, mid height and top, is always observed to be increasing with the increase of aspect ratio. Adjacent to the cold wall, the velocity curves become meander for aspect ratio greater than 3 (Figure 11b).

Table 2. Mass flow and temperature for different AR

\begin{tabular}{|c|c|c|c|c|c|c|c|c|}
\hline $\begin{array}{l}\text { Aspect } \\
\text { Ratio } \\
\text { (AR) }\end{array}$ & $\begin{array}{c}\text { Mass flow } \\
\text { (bottom) }(\mathrm{Kg} / \mathrm{s}) \\
\times 10^{-6}\end{array}$ & $\begin{array}{l}\text { Mass flow } \\
\text { (Top) }(\mathrm{Kg} / \mathrm{s}) \\
\times 10^{-6}\end{array}$ & $\begin{array}{l}\text { Error } \\
(\%) \\
\times 10^{-3} \\
\end{array}$ & $\begin{array}{l}\text { Error in mass } \\
\text { flow with } \\
\text { AR-2 (\%) }\end{array}$ & $\begin{array}{l}\text { Temperature } \\
\text { (Bottom) }(\mathrm{K})\end{array}$ & $\begin{array}{l}\text { Temperature } \\
(\text { Top) }(\mathrm{K})\end{array}$ & $\begin{array}{c}\text { Error }(\%) \\
\times 10^{-1}\end{array}$ & $\begin{array}{c}\text { Error in } \\
\text { temperature with } \\
\text { AR-2 }(\%) \times 10^{-3}\end{array}$ \\
\hline 1 & 0.66119 & 0.66115 & 5.445 & 47.156 & 298.169 & 299.562 & 4.672 & 2.348 \\
\hline 2 & 1.25120 & 1.25117 & 2.398 & 0 & 298.162 & 300.244 & 6.983 & 0 \\
\hline 3 & 1.67561 & 1.67559 & 1.194 & 33.920 & 298.158 & 300.444 & 7.667 & 1.342 \\
\hline 4 & 2.3779 & 2.37788 & 0.841 & 90.05 & 298.156 & 300.441 & 7.664 & 2.012 \\
\hline 5 & 3.1957 & 3.19566 & 1.252 & 155.41 & 298.155 & 300.396 & 7.516 & 2.348 \\
\hline
\end{tabular}

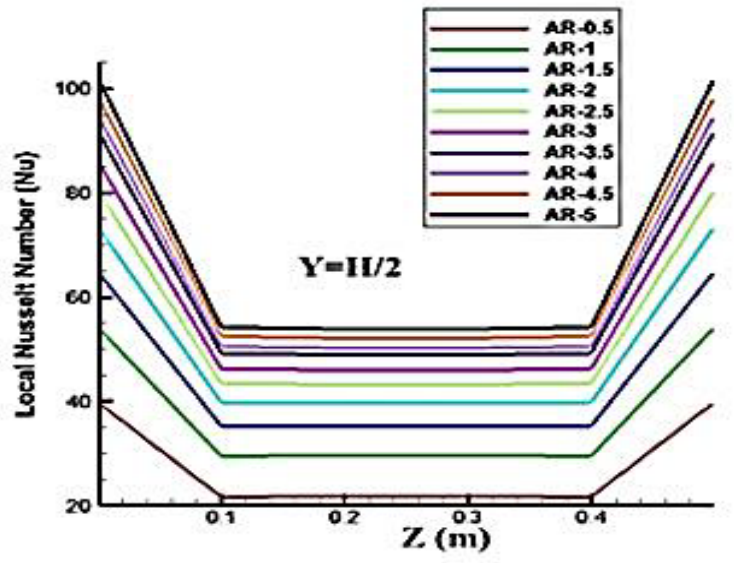

(a)

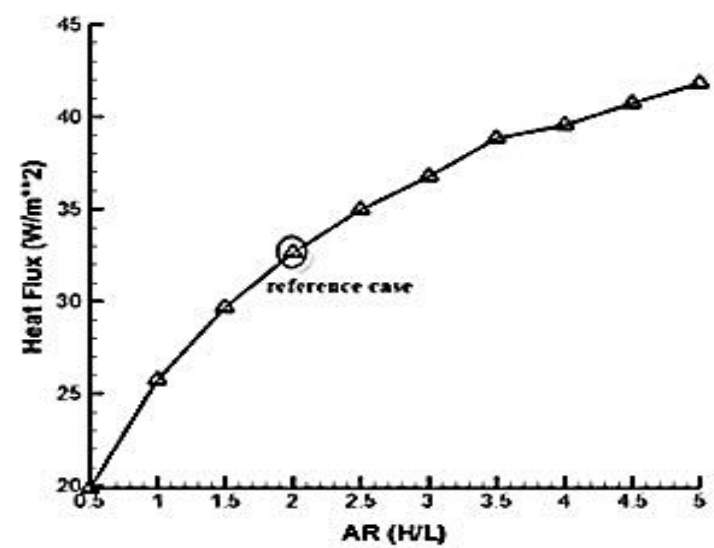

(b)

Figure 10. (a) Local Nusselt number for different AR at mid height of the hot wall and (b) Change of Heat flux for different AR at the hot wall

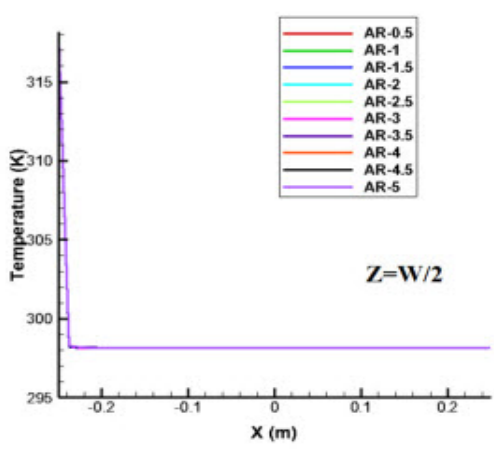

$y=-0.5 m$
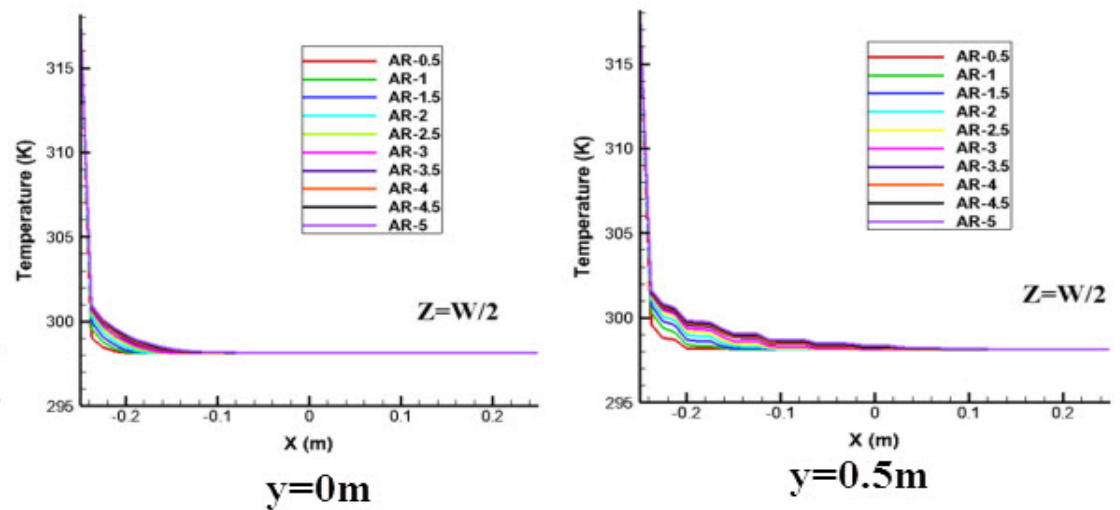

Figure 11. (a) Temperature profile at different height of the cavity
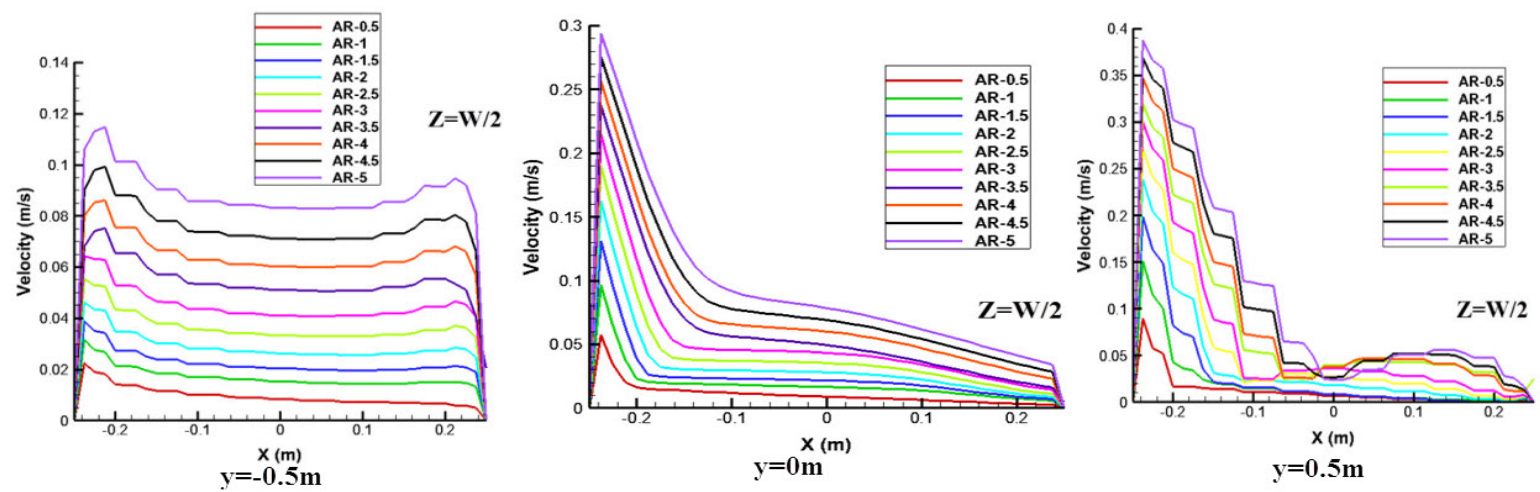

Figure 11. (b) Velocity profile at different height of the cavity 


\subsection{Effects of Temperature Difference}

Temperature difference between the hot and cold wall is an important condition to capture the flow pattern inside the cavity. Different temperature differences varying from $5 \mathrm{~K}$ to $35 \mathrm{~K}$ have been used in this section. It is done by changing the hot wall temperature from $35^{\circ} \mathrm{C}$ to $60^{\circ} \mathrm{C}$ and the cold wall temperature is kept unchanged $\left(25^{\circ} \mathrm{C}\right)$. Table 3 shows the effects of temperature differences on average mass flow and temperature. Average mass flow at the bottom wall of the cavity increases with the increase of temperature difference. The temperature at the bottom wall also slightly increases with the increase of temperature difference. Figure 13 shows the velocity profile at different height of the cavity. The velocity increases with the increase of temperature difference (hot wall temperature) and the velocity is higher adjacent to the hot wall.

The deviation of average temperature from the imposed temperature is observed by using the respective average heat flux at left wall instead of temperature. It is found that this deviation (\%) is very small and it increases with the increase of temperature as well as heat flux (Figure 14) at left wall.
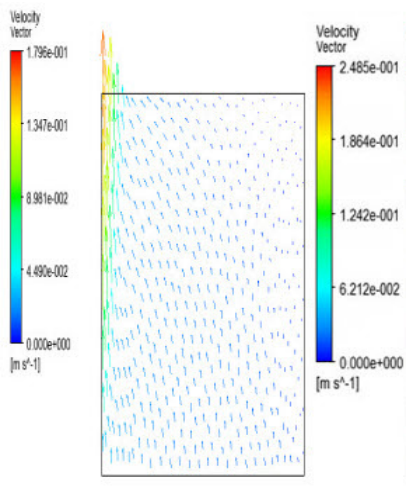

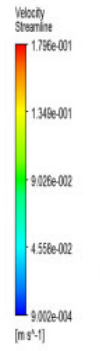

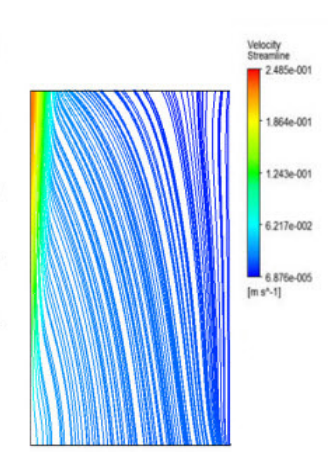

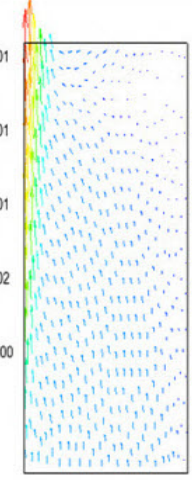
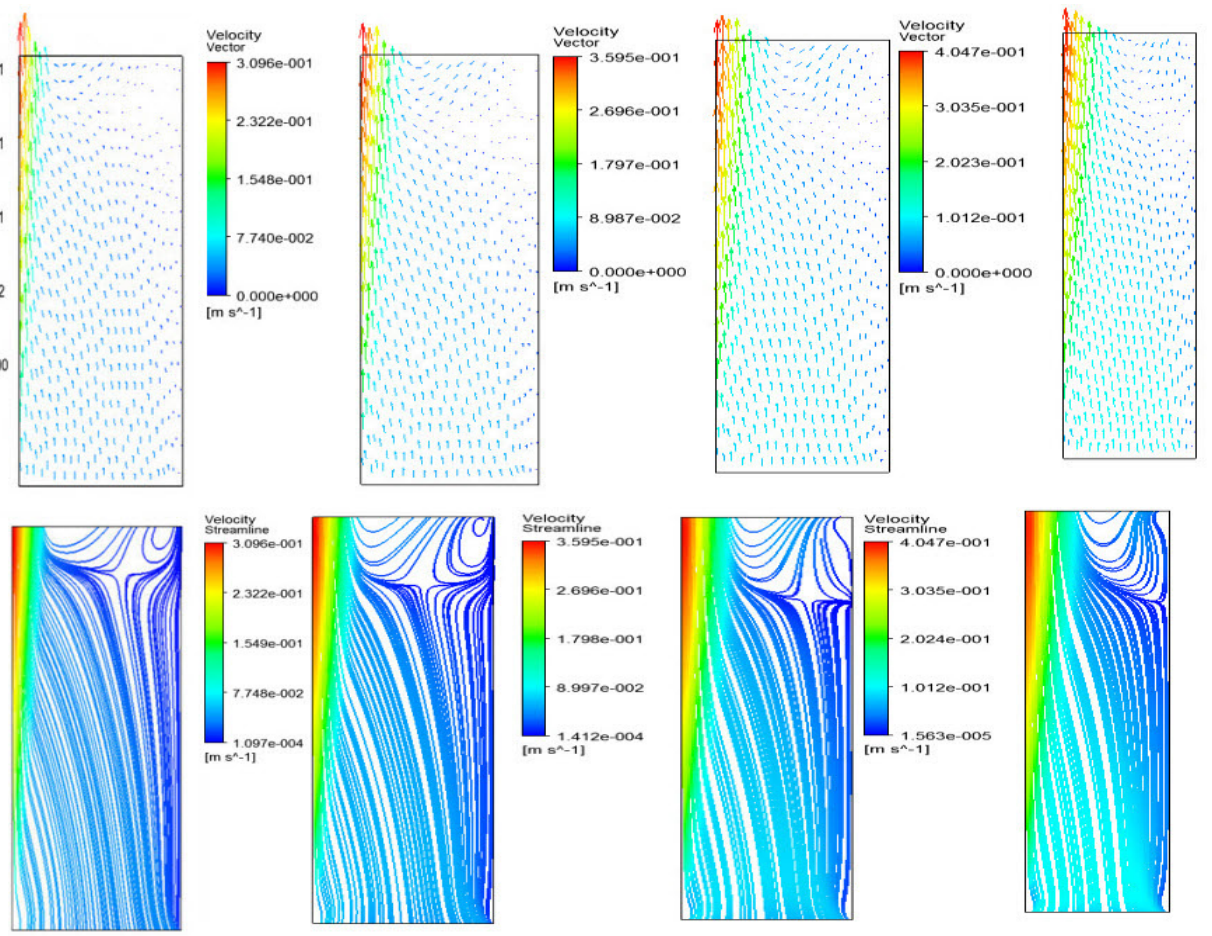

$\underline{L}=$

Figure 12. Velocity vectors and streamlines for different aspect ratio (AR-1, AR-2, AR-3, AR-4 and AR-5 respectively)

Table 3. Mass flow and temperature for different temperature difference

\begin{tabular}{|c|c|c|c|c|c|c|c|c|}
\hline $\begin{array}{c}\text { Temperature } \\
\text { difference }(\mathrm{K})\end{array}$ & $\begin{array}{c}\text { Mass flow } \\
\text { (bottom) } \\
(\mathrm{Kg} / \mathrm{s}) \times \\
10^{-6} \\
\end{array}$ & $\begin{array}{l}\text { Mass flow } \\
\text { (Top) }(\mathrm{Kg} / \mathrm{s}) \\
\times 10^{-6}\end{array}$ & $\begin{array}{l}\text { Error }(\%) \\
\quad \times 10^{-3}\end{array}$ & $\begin{array}{l}\text { Error in mass } \\
\text { flow with } \\
\text { reference case } \\
(\%)\end{array}$ & $\begin{array}{l}\text { Temperature } \\
\text { (Bottom) }(\mathrm{K})\end{array}$ & $\begin{array}{l}\text { Temperature } \\
\text { (Top) (K) }\end{array}$ & $\begin{array}{c}\text { Error } \\
(\%) \times \\
10^{-1}\end{array}$ & $\begin{array}{c}\text { Error in } \\
\text { temperature with } \\
\text { reference }(\%) \times \\
10^{-3}\end{array}$ \\
\hline 5 & 0.66083 & 0.66083 & 0 & 47.18 & 298.154 & 298.69 & 1.7977 & 2.683 \\
\hline 10 & 0.86197 & 0.86197 & 0 & 31.17 & 298.156 & 299.282 & 3.7766 & 2.012 \\
\hline 15 & 1.11283 & 1.11281 & 1.797 & 11.06 & 298.159 & 299.704 & 5.1818 & 1.006 \\
\hline 20 & 1.2512 & 1.2517 & 2.398 & 0 & 298.162 & 300.244 & 6.9828 & 0 \\
\hline 25 & 1.37181 & 1.3718 & 2.187 & 9.64 & 298.164 & 300.784 & 8.7871 & 0.671 \\
\hline 30 & 1.47896 & 1.47893 & 2.028 & 18.20 & 298.166 & 301.327 & 10.601 & 1.342 \\
\hline 35 & 1.57633 & 1.57629 & 2.538 & 25.99 & 298.168 & 301.872 & 12.423 & 2.012 \\
\hline
\end{tabular}
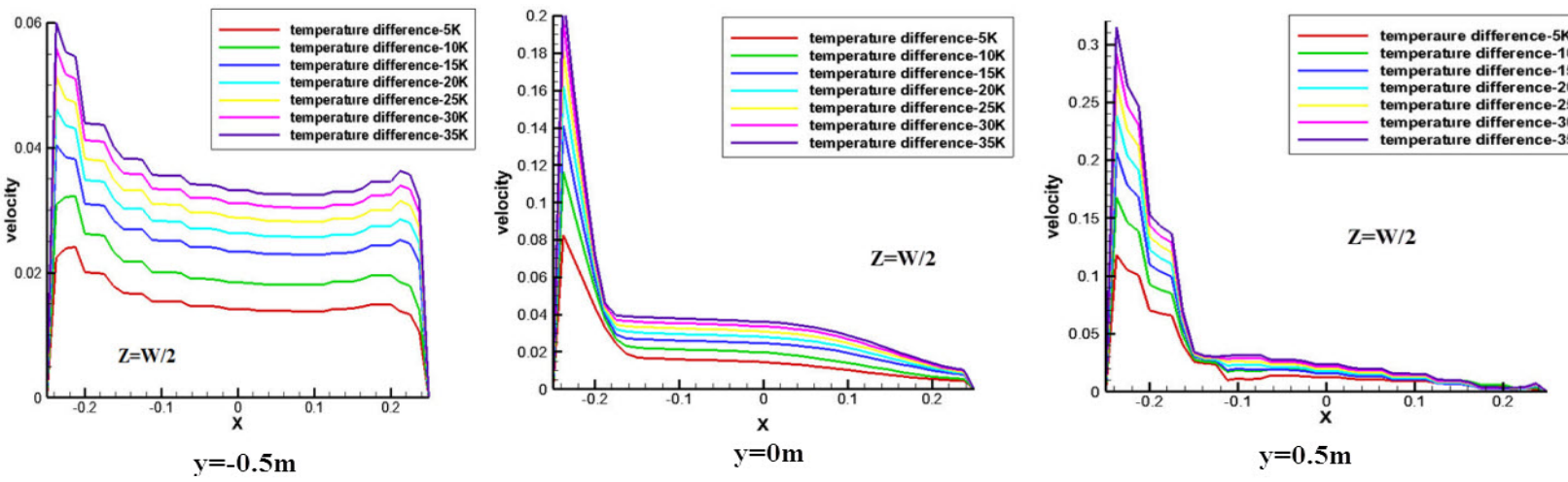

Figure 13. Velocity profile at different height of the cavity for different temperature difference 


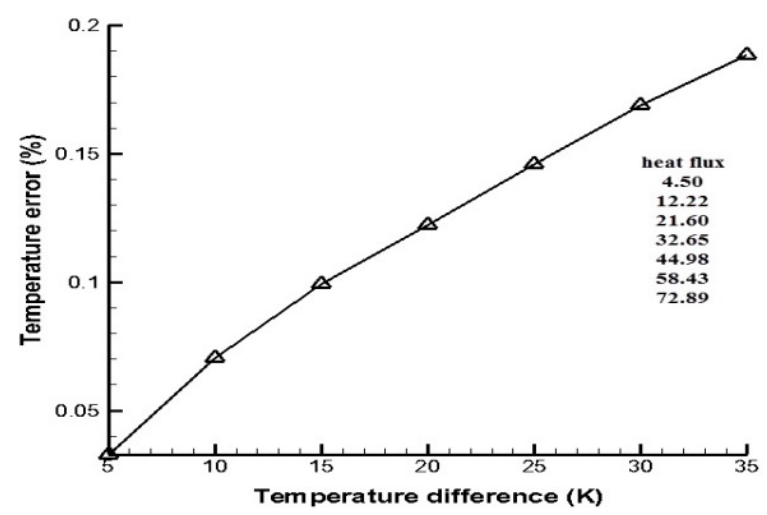

Figure 14. Deviation (\%) of average temperature from the imposed temperature at left wall

Figure 15 shows the streamlines on a vertical plane at mid width of the cavity. It is observed that the flow at the top of adjacent to the cold wall is more turbulent for low temperature differences. With the increase of temperature difference, this turbulent behavior adjacent to the cold wall of the flow inside the cavity decreases. Since with the increase of temperature difference inside the cavity, the velocity of the flow also increases and so the flow becomes less turbulent. For temperature difference greater than $20 \mathrm{~K}$ the difference in streamlines is not so much visible. The effects of temperature difference are more significant for low temperature difference than the high temperature differences since the velocity of the flow is lower for low temperature difference.

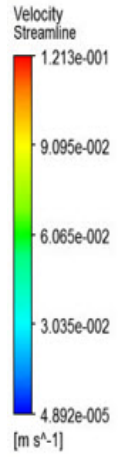

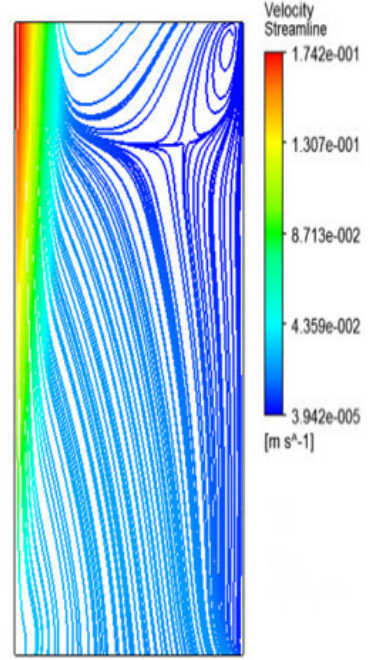

$5 \mathrm{~K}$

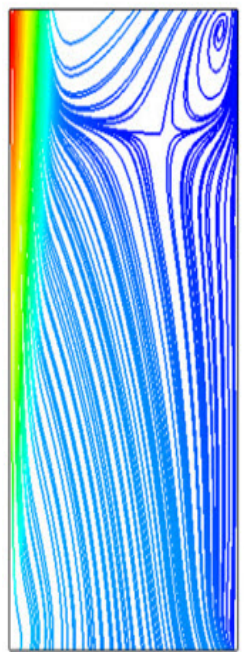

$10 \mathrm{~K}$
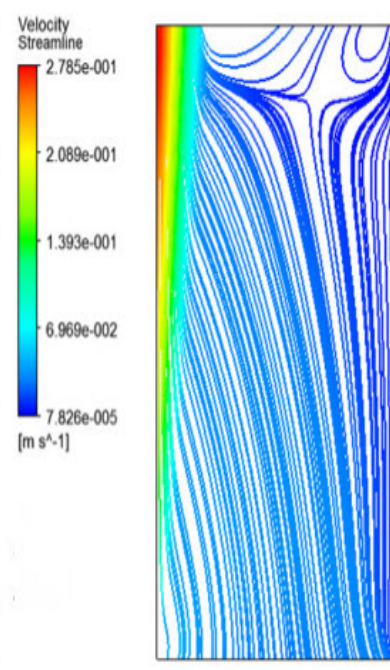

$25 \mathrm{~K}$

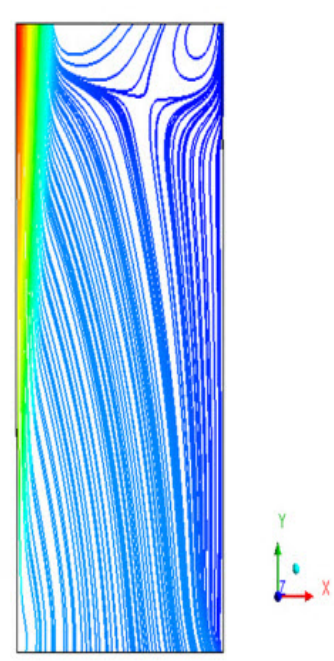

$35 \mathrm{~K}$

Figure 15. Streamlines on a vertical plane at mid width of the cavity for different temperature differences 


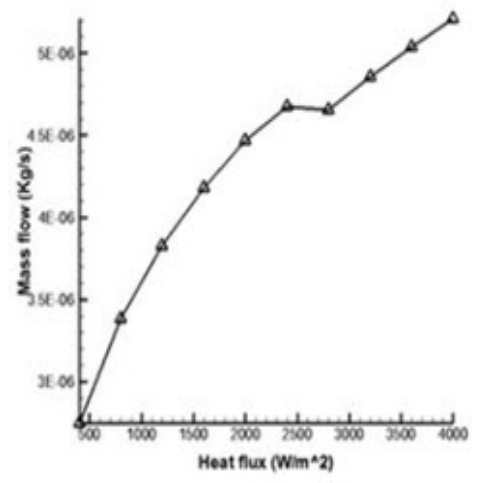

(a)

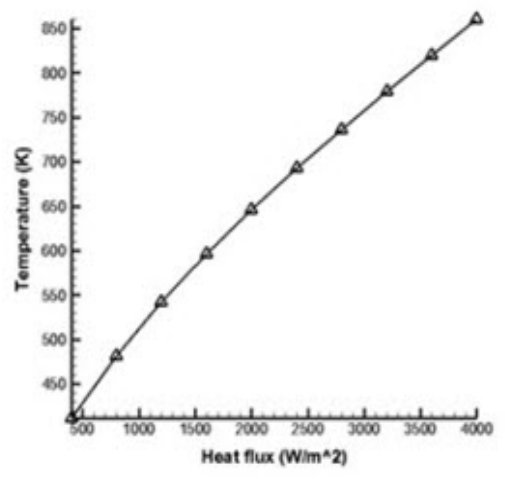

(b)

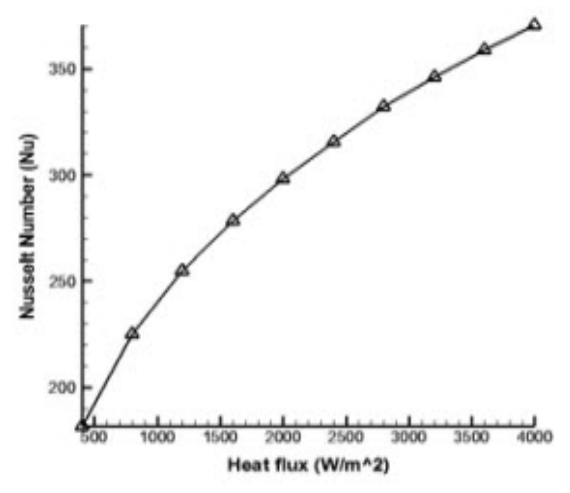

(c)

Figure 16. (a) Mass flow at bottom wall (b) Temperature at left wall and (c) Nusselt number at hot wall of the cavity at different heat flux

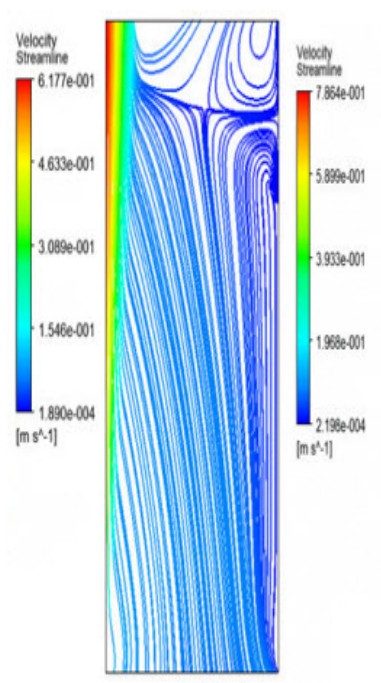

$400 \mathrm{~W} / \mathrm{m}^{2}$

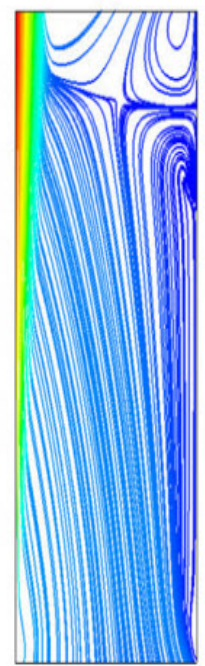

$800 \mathrm{~W} / \mathrm{m}^{2}$

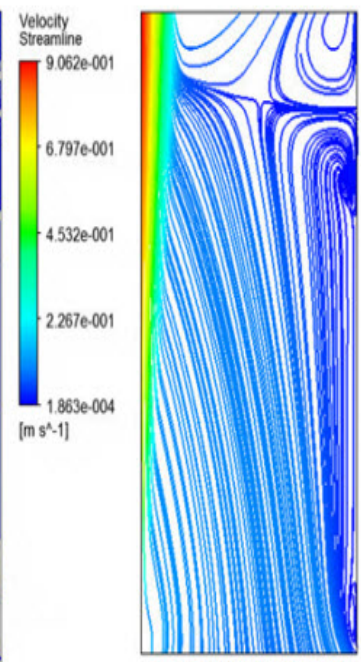

$1200 \mathrm{~W} / \mathrm{m}^{2}$
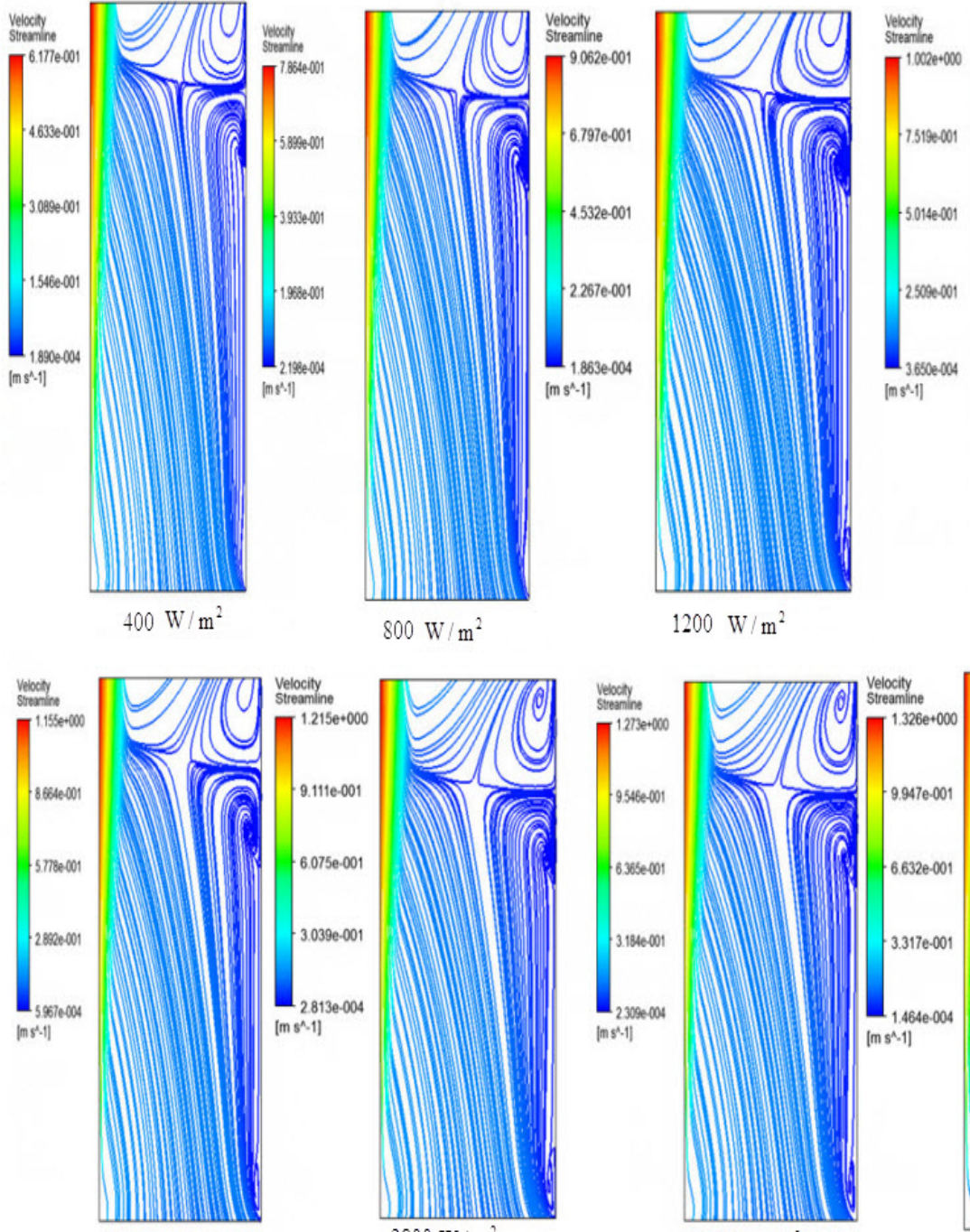

$2400 \mathrm{~W} / \mathrm{m}^{2}$

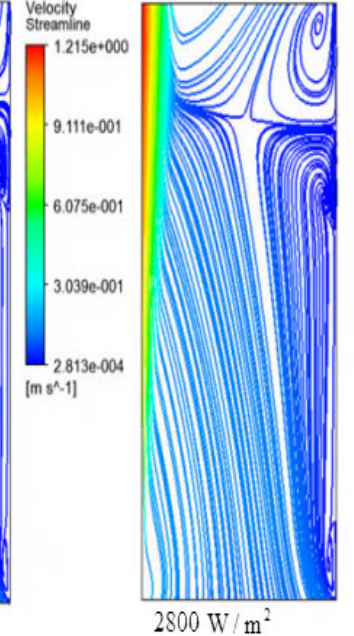

$2800 \mathrm{~W} / \mathrm{m}^{2}$

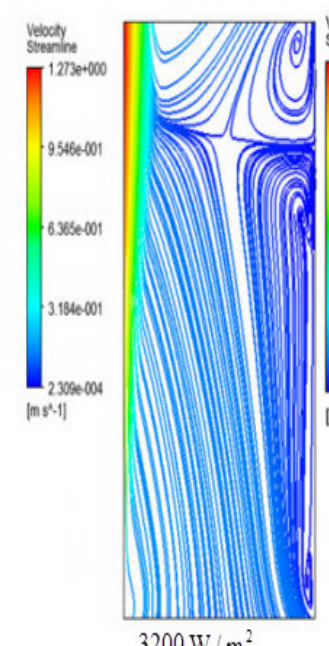

$3200 \mathrm{~W} / \mathrm{m}^{2}$

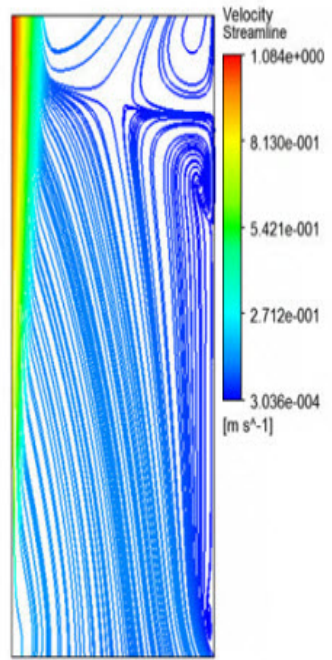

$1600 \mathrm{~W} / \mathrm{m}^{2}$

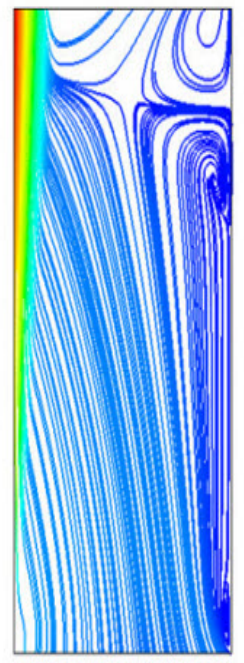

$2000 \mathrm{~W} / \mathrm{m}^{2}$

Figure 17. Streamlines on a vertical plane at different heat flux

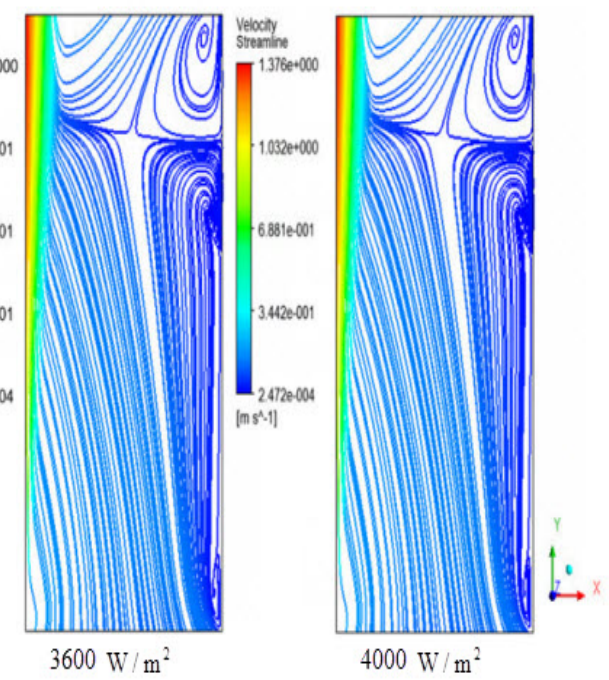




\subsection{Relations and Comparisons of Non-dimensional Parameters}

The phenomenon of natural convection in an enclosure or cavity is as varied as the geometry and orientation of the enclosure or cavity. Convection in an enclosure is the result of the complex interaction between finite-size fluid systems in thermal communication with all the walls that confine it. Non-dimensional parameters are important to study, to understand the physics of the model clearly.

In this section, a relation among the non-dimensional parameters such as Nusselt number, Rayleigh number, Prandlt number is established.

Bejan [22] proposed a relation 7 between Nusselt number and Rayleigh number for all temperature difference and heat flux. If the wall condition is of uniform heat flux, the coefficient 0.19 is replaced by 0.198 .

$$
N u_{h}=\frac{h_{0-H^{H}}}{k} \cong 0.19 R a_{H}^{1 / 3} \operatorname{Pr}^{1 / 3} \quad(\operatorname{Pr} \ll 1)
$$

Here, $h_{0-H}=2.08201 \mathrm{Wm}^{-2} K^{-1}$ is the heat transfer coefficient averaged over the wall height $\mathrm{H}$ and $\mathrm{Ra}_{\mathrm{H}}$ is the Rayleigh number based on $\mathrm{H}$ and $\left(T_{0}-T_{\infty}\right) \cdot \mathrm{Ra}_{\mathrm{H}}$ is computed by the following formulas:

$$
R a_{H}=\frac{g \beta \Delta T H^{3} \mathrm{Pr}}{v^{2}}
$$

$\mathrm{Nu}$ number and Ra number in the present study is found to be related as follows:

$$
N u_{h}=\frac{h_{0-H} H}{k} \cong 0.073 \operatorname{Ra}_{H}^{1 / 3} \operatorname{Pr}^{1 / 3} ;(\operatorname{Pr} \ll 1)
$$

Figure 18 shows the changing Nusselt numbers for different Rayleigh number with the coefficient 0.073 .

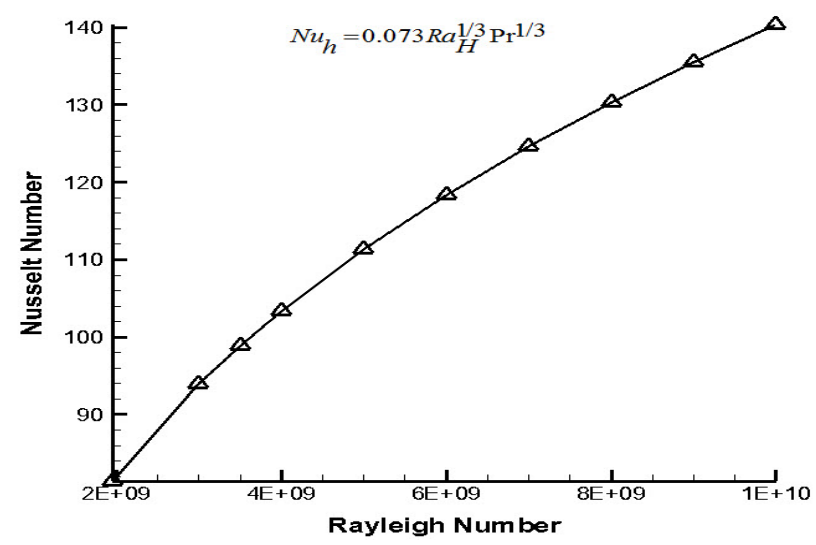

Figure 18. Relation between Nusselt number and Rayleigh number

Dittus-Boelter correlation [22] represents a relation between Nusselt number, Prandtl number and Reynolds number for a fully developed turbulent flow in a long pipe or tube. This relation is proposed for a smooth wall cavity with Prandlt number 0.7-100 and Reynolds number greater than 10000. But this relation can also be used for lower Reynolds Number.

The proposed correlation for a heating flow is as follows:

$$
N u=0.023 \mathrm{Re}^{0.8} \operatorname{Pr}^{0.4}
$$

The flow in the present study is turbulent, but not fully developed. In eqn. 10 the aspect ratio is considered to be greater or equal 60 . But in the present study aspect ratio is assumed to be 2 and the flow is in an open cavity instead of a pipe. So discrepancy is observed with eqn. 10. This relation for the present study is found to be as follows:

$$
N u=0.213 \operatorname{Re}^{0.8} \operatorname{Pr}^{0.4}
$$

Where, Reynolds number $\operatorname{Re}=\frac{U H}{v} \approx 2014$;

$\mathrm{U}=0.031461 \mathrm{~m} / \mathrm{s}$, is the mean velocity of the fluid. Fig. 19 shows the Nusselt number for different Reynolds number.

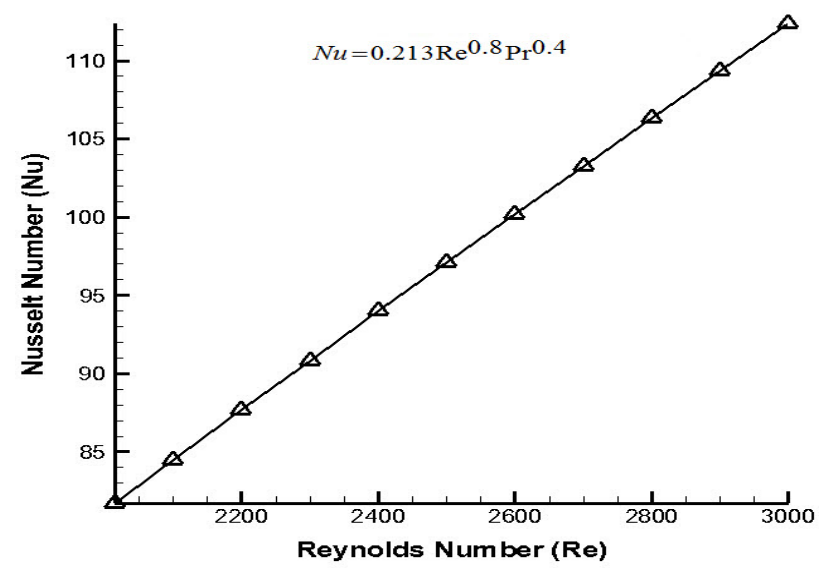

Figure 19. Relation between Nusselt number and Reynolds number

\section{Conclusions}

The heat transfer phenomenon in open cavity has become an important topic to study. The development of turbulence modeling and the increase of computer speed have made CFD an alternative and popular approach due to its informative result, low labor and low cost. In any specific CFD approach, the proper turbulence model and boundary conditions are the prerequisite to simulate the buoyancy driven flow in the open cavity. Effects of different boundary conditions on buoyancy driven natural convection flow in a three dimensional open cavity is studied here numerically. It is observed from this study, that the solution captures the flow and heat transfer phenomena near the walls quite well. To validate the present numerical methodology and the code, two comparisons are made with published data and satisfactory agreements are found. 
It is observed that the flow and heat transfer characteristics depend on boundary conditions. The flow adjacent to the cold wall is observed to be more turbulent for lower temperature difference between the hot and cold walls. Turbulent behavior, mass flow and the velocity of the flow adjacent to the hot and cold walls are observed to be increasing with the increase of cavity size and heat flux imposing. To capture the turbulent behavior inside the cavity $k-\varepsilon$ turbulence model is used. In order to determine the heat transfer characteristics inside the cavity, two relations among Nusselt number, Reynolds number and Rayleigh number are established and compared with relations proposed in literature. $\mathrm{Nu}$ number and Ra number is found to be $\mathrm{Nu}_{\mathrm{H}}=0.073 \mathrm{Ra}_{\mathrm{H}}{ }^{1 / 3} \operatorname{Pr}^{1 / 3}$. It is also found that Nusselt number and Reynolds number are related by the equation $\mathrm{Nu}=0.023 \mathrm{Re}^{0.8} \mathrm{Pr}^{0.4}$. The discrepancy between these coefficients with those in literature is found because unlike the flows considered in the literature, the flow considered in this study is not fully developed.

In case of Nusselt and Reynolds number relation the aspect ratio is so much less than the proposed cases may be because of the geometry which is considered in an open cavity instead of a pipe flow. It may be concluded that this relation can't be used for both the cavity and pipe flow. Not fully developed flow may also be a reason.

A cavity is similar to a room of a building in broader sense with its windows and doors as closed. Using the opening condition at the doors and windows it is possible to capture the flow phenomena in a room as well as in a building, which may be the future work. By using natural ventilation system in residential buildings, the world may become more developed by saving so much electric power and its cost.

\section{REFERENCES}

[1] Peng Wang, Yonghao Zhan, Zhaoli Guo, Numerical study of three-dimensional natural convection in a cubical cavity at high Rayleigh numbers, International Journal of Heat and Mass Transfer, 113 (2017) 217-228.

[2] N.C. Markatos and K. A. Pericleous, Laminar and turbulent natural convection in an enclosed cavity, International Journal of Heat and Mass Transfer, Vol. 27, 755- 772, 1984.

[3] G. De Vahl Davis, Natural convection of air in a square cavity: a benchmark numerical solution, International Journal of Numerical Methods of Fluids, Vol. 3, 249-264, 1983.

[4] Aswatha, C.J. Gangadhara Gowda, S.N. Sridhara, K.N. Seetharamu, Effect of convective boundary conditions at bottom wall on natural convection in a square cavity, Journal of Engineering Science and Technology, Vol. 8, No. 2, 141 $164,2013$.

[5] Ayla Dogan, S. Baysal and Senol Baskaya, Numerical analysis of natural convection heat transfer from partially open cavities heated at one wall, Journal of thermal science and technology, Is1 Bilimi ve Tekniği Dergisi, Vol. 29, 1, 79-90, 2009.
[6] N. Alpay Kurekci and Oktay Ozkan, An experimental and numerical study of laminar natural convection in a differentially - heated cubical enclosure, Journal of Thermal Science and Technology Isı Bilimi ve Tekniği Dergisi, Vol. 32, 1, 1-8, 2012.

[7] Y. Jiang, D. Alexander, H. Jenkins, R. Arthur, Q. Chen, Natural ventilation in buildings: measurements in a wind tunnel and numerical simulation with large-eddy simulation, Journal of Wind Engineering and Industrial Aerodynamics, Vol. 91, 331-353, 2003.

[8] Wei Zhang, Qingyan Chen, Large eddy simulation of indoor air flow with a filtered dynamic subgrid scale model, International Journal of Heat and Mass Transfer, Vol. 43, 3219-3231, 2000.

[9] H.S. Lee, J.H. Jung and H.S. Yoon, A numerical study of three dimensional natural convection in a differentially heated cubical enclosure, Proceedings of the 2013 International Conference on Mechanics, Fluids, Heat, Elasticity and Electromagnetic Fields, 2013.

[10] C. Kettleborough, Transient laminar free convection between heated vertical plates including entrance effects, International Journal of Heat and Mass Transfer Vol. 15, 883-896, 1972.

[11] D. Naylor, J. Floryan, J. Tarasuk, A numerical study of developing free convection between isothermal vertical plates, Journal of Heat Transfer Vol. 113, 620-626, 1991.

[12] Abdullah A.A.A Al-Rashed, Lioua Kolsi, Ahmed Kadhim Hussein, Walid Hassen, Mohamed Aichouni, Mohamed Naceur Borjini, Numerical study of three-dimensional natural convection and entropy generation in a cubical cavity with partially active vertical walls, Case Studies in Thermal Engineering 10 (2017) $100-110$.

[13] Aswatha, C.J. Gangadhara Gowda, S.N. Sridhara, K.N. Seetharamu, Effect of aspect ratio and thermal boundary conditions on natural convection in open cavities, Proceedings of the 37th National \& 4th International Conference on Fluid Mechanics and Fluid Power, IIT Madras, Chennai, India, December 16-18, 2010.

[14] ANSYS 12.0, Ansys Inc., User manual.

[15] A. Bejan, S. Kimura, Penetration of free convection into a lateral cavity, Journal of Fluid Mechanics Vol. 103, 465-478, 1981.

[16] K. Khanafer, K. Vafai, Effective boundary conditions for buoyancy-driven flows and heat transfer in fully open-ended two-dimensional enclosures, International Journal of Heat and Mass Transfer Vol. 45, 2527-2538, 2001

[17] C. Evola, V. Popov, Computational analysis of wind driven natural ventilation in buildings, Energy and Buildings Vol. 38, 491-501, 2006.

[18] M.Z.I. Bangalee, J.J. Miau, S.Y. Lin, Computational techniques and a numerical study of a buoyancy-driven ventilation system, International Journal of Heat and Mass Transfer Vol. 65, 572-583, 2013.

[19] C. Allocca, Q. Chen, L. R. Glicksman, Design analysis of single-sided natural ventilation, Energy and Buildings Vol. 35, 785-795, 2003. 
[20] V. M. Maytorena, A. Piña-Ortiz \& J. F. Hinojosa, Experimental and numerical study of turbulent natural convection in an open cubic cavity, Heat Mass Transfer (2015) DOI 10.1007/s00231-014-1492-0.

[21] G. Barakos, E. Mitsoulis and D. Assimacopoulos, Natural Convection Flow in A Square Cavity Revisited: Laminar and Turbulent Models with Wall Functions, International Journal for Numerical Methods in Fluids Vol. 18, 695-719, 1994.

[22] A. Bejan, Convection Heat Transfer, Fourth Edition, John Wiley \& Sons, Durham, North Carolina, 2013.
[23] Guohui Gan, Simulation of buoyancy-driven natural ventilation of buildings-Impact of computational domain, Energy and Buildings, Vol. 42, 1290-1300, 2010.

[24] I. G. Currie, Fundamental Mechanics of Fluids, Third Edison, Marcel Dekker, Inc., New York, Basel, 2003.

[25] Y.A. Cengel, Heat Transfer a Practical Approach, Second Edison, Mc Graw Hill, New York, 2004.

[26] Guohui Gan, Impact of computational domain on the prediction of buoyancy-driven ventilation cooling, Building and Environment, Vol. 45, 1173-1183, 2010. 